\title{
Modeling blood-brain barrier pathology in cerebrovascular disease in vitro: current and future paradigms
}

\author{
Anuska V. Andjelkovic ${ }^{1 *}$, S Svetlana M. Stamatovic ${ }^{1}$, Chelsea M. Phillips ${ }^{4}$, Gabriela Martinez-Revollar ${ }^{1}$ \\ and Richard F. Keep ${ }^{2,3}$
}

\begin{abstract}
The complexity of the blood-brain barrier (BBB) and neurovascular unit (NVU) was and still is a challenge to bridge. A highly selective, restrictive and dynamic barrier, formed at the interface of blood and brain, the BBB is a "gatekeeper" and guardian of brain homeostasis and it also acts as a "sensor" of pathological events in blood and brain. The majority of brain and cerebrovascular pathologies are associated with BBB dysfunction, where changes at the BBB can lead to or support disease development. Thus, an ultimate goal of BBB research is to develop competent and highly translational models to understand mechanisms of BBB/NVU pathology and enable discovery and development of therapeutic strategies to improve vascular health and for the efficient delivery of drugs. This review article focuses on the progress being made to model BBB injury in cerebrovascular diseases in vitro.
\end{abstract}

Keywords: Stroke, In vitro models, Neurovascular units, Blood-brain barrier, Vascular dementia, Brain vascular malformation

\section{Introduction}

\section{Cerebrovascular diseases}

Cerebrovascular diseases are the most common lifethreatening neurological events and represent the second leading cause of mortality worldwide, fifth leading cause of death in USA and are a leading cause of long-term disability. Despite improved lifestyle and lowering of risk factors (hypertension and smoking), cerebrovascular disease still represents a threatening factor, particularly with an aging population. Aging is a robust non-modifiable risk factor, with a doubling in the incidence of cerebrovascular disease (i.e. stroke) for every 10 years [1]. Thus, an aging population is a major challenge for the foreseeable future.

*Correspondence: anuskaa@med.umich.edu

1 Department of Pathology, University of Michigan Medical School, 7520 MSRB I, 1150 West Medical Center Dr, Ann Arbor, MI 48109-5602, USA

Full list of author information is available at the end of the article
Cerebrovascular disease includes ischemic and hemorrhagic stroke, vascular malformations and vascular dementia (Fig. 1). These conditions can reduce cerebral blood flow, due to vessel narrowing, thrombosis or emboli, as well as causing vessel rupture. Cerebrovascular diseases are subdivided into pathologies impacting large and medium or small caliber blood vessels. Cerebral small vessels disease affects small caliber arteries, arterioles, capillaries and venules, and is a major cause of stroke and vascular dementia in the elderly.

Stroke is defined as a sudden onset of focal or global neurological symptoms caused by cession of blood flow due to blockage of cerebral vessels (ischemic stroke), transient occlusion of small blood vessels (transient ischemic attack, TIA) or rupture of blood vessels (hemorrhage). Ischemic stroke ( $87 \%$ of all cases) is subdivided based on the (a) caliber of occluded vessels into macroand microvascular (i.e. lacuna stroke), and (b) origin of clot-causing blockage into thrombotic stroke-clot form inside brain blood vessels, and thromboembolic/embolic 


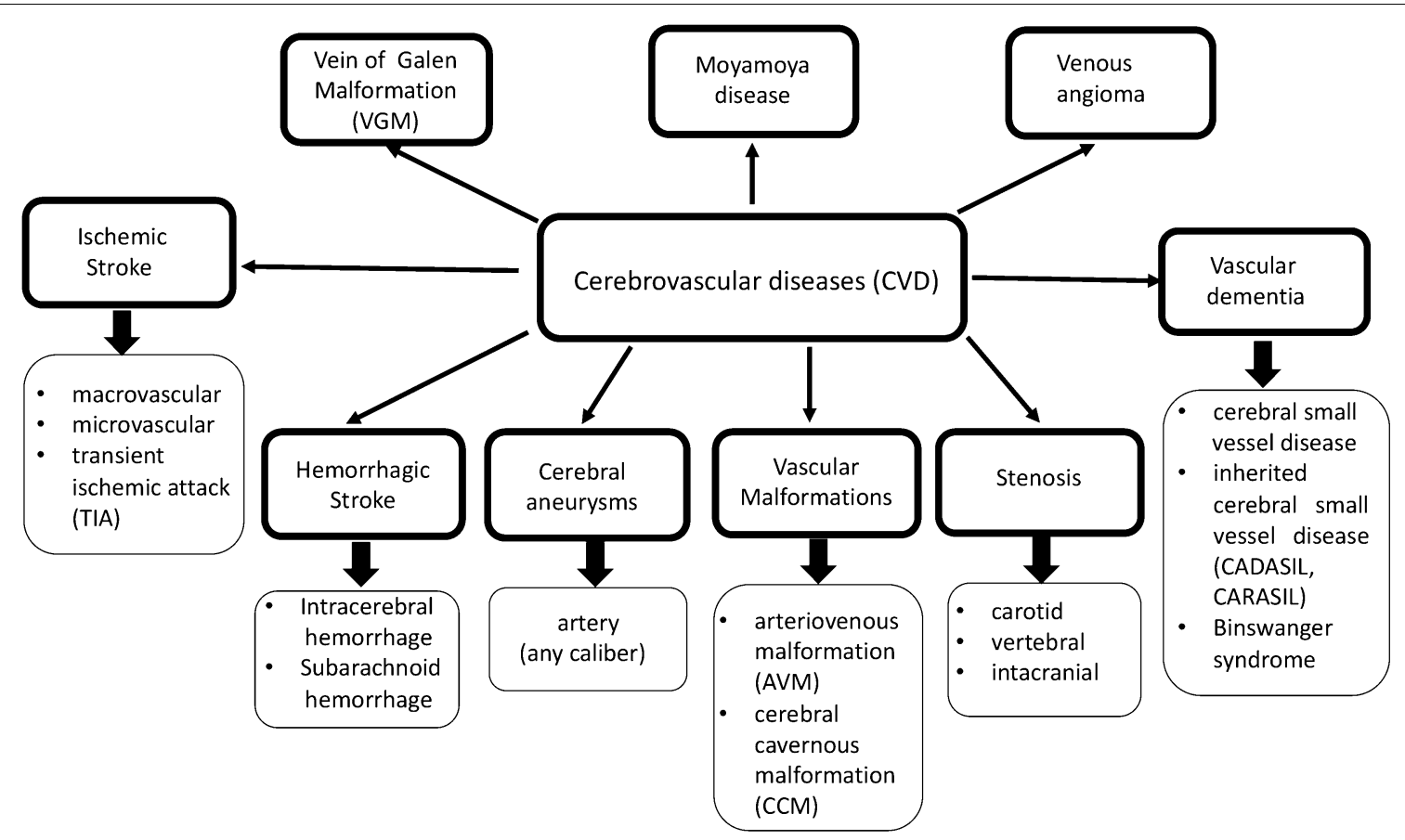

Fig. 1 Flowchart summarizing clinical classification of cerebrovascular disease

stroke-clots form elsewhere in the body and travel towards and lodge in brain blood vessels [2-4]. TIAs are sudden brief neurological deficits due to partial occlusion of cerebral blood vessels that resolve without any residual symptoms or signs [3]. The tissue changes may vary from ischemia-tolerant state to silent stroke injury. Repeated TIA episodes can lead to cognitive decline or brain atrophy $[5,6]$. Hemorrhagic stroke (13\% of all cases) is characterized by rupture of blood vessels resulting in bleeding into the brain parenchyma (intracerebral hemorrhage; $\mathrm{ICH}$ ), subarachnoid space (subarachnoid hemorrhage; $\mathrm{SAH}$ ) or ventricular system (intraventricular hemorrhage) $[3,7]$. Aging, hypertension and diabetes are all risk factors for hemorrhagic stroke [3].

Vascular malformations are idiopathic or inherited defects in cerebral blood vessels that can cause hemorrhagic stroke, epilepsy and focal neurological deficits. Evidence indicates that a major cause of these malformations is a defect in angiogenesis which may be altered due to genetic mutations and/or environmental influences [8-10]. These result in vessel wall instability and absence of perivascular cell recruitment [11]. The most common forms are arteriovenous malformations (AVMs), cerebral cavernous malformations (CCMs) and hereditary hemorrhagic telangiectasia (HHT). While AVMs affect arteries, veins, and middle-sized vessels, CCMs and HHT primarily affect capillaries with a tendency to progress to arterial and venules (CCMs) [8-10].
Vascular dementia $(\mathrm{VaD})$ is a cognitive deficit disorder caused by impaired blood flow and vascular injury. This is the second most common type of dementia after Alzheimer's disease (AD), accounting for $10-20 \%$ of all cases of dementia with a steady increased rate after 65 years of age $[12,13]$. There is also evidence that some dementia patients have both $\mathrm{VaD}$ and $\mathrm{AD}$ (mixed dementia). Risk factors associated with $\mathrm{VaD}$ are hypertension, atrial fibrillation, prior history of stroke, diabetes mellitus and smoking [12, 14, 15]. The pathophysiology/pathology of $\mathrm{VaD}$ is complex but it often presents as vasculitis in big and small caliber brain vessels [15].

Another condition, closely associated with $\mathrm{VaD}$, is cerebral small vessel disease. It predominantly affects brain arterioles and capillaries leading to reduced brain perfusion, blood-brain barrier (BBB) damage, lacunar infarcts and dementia [13]. Thus, in Binswanger syndrome, there are thromboembolic strokes with atherosclerosis of the small caliber vessels in white matter [16]. Some cerebral small vessel disease is inherited: cerebral autosomal dominant arteriopathy with subcortical infarct and leukoencephalopathy (CADASIL) and cerebral autosomal recessive arteriopathy with subcortical infarcts and leukoencephalopathy (CARASIL) [17]. These are caused by mutations in NOTCH 3 genes in arteriole smooth muscle cells and mutations in HTRA1, respectively [18-20]. Both conditions are characterized by multiple and recurrent stroke or TIA and progressive cognitive impairment 
starting from age of 40-50 years (CADASIL) and 20-mid $40 \mathrm{~s}$ (CARASIL) [17, 20].

\section{Cerebrovascular networks: structure, composition and unique features}

The brain has a high demand for oxygenated blood. Thus, it receives $\sim 15 \%$ of cardiac output with a blood flow of $\sim 50 \mathrm{~mL} / \mathrm{min}$ per $100 \mathrm{~g}$ brain in man. This high demand has resulted in the development of specific cerebral blood vessel networks with arteriovenous hierarchy. Brain blood supply is via two pairs of arteries: right and left common carotid arteries and right and left vertebral arteries. Each common carotid artery divides into the external carotid artery (face and scalp) and internal carotid artery a principal blood supplier of cerebrum. The conjunction of two vertebral arteries form the basilar artery that supply blood to posterior part of cerebrum, part of cerebellum and brain stem. The basilar artery and two internal carotid arteries form the anastomotic ring at the base of the brain (circle of Willis) from which arises the anterior, middle, and posterior cerebral arteries that branch to smaller arteries and arterioles, which run along the surface and then penetrate into brain parenchyma $[21,22]$. The vascular tree branches further into arterioles and capillaries and the area of the vascular bed is increased dramatically, slowing the blood and allowing diffusion of oxygen and other capillary exchange. In particular, the capillary bed is a dense network of intercommunicating vessels that consist of specialized endothelial cells and perivascular cells denoted as the neurovascular unit (NVU). The total length of capillaries in the human brain is 400 miles [22]. The venous network also includes a complex network of sinuses that drain blood to the jugular vein to exit brain $[21,23]$.

There are several characteristics of the cerebrovascular system that are important for cerebrovascular pathology. First, the cerebrovascular network includes anastomoses (i.e. circle of Willis and the pial network) which exist between arteries, veins or arteries and veins [22, 23]. These structures help preserve cerebral circulation if vessels are occluded. Second, the extraordinary dense network of capillaries with shorter, more numerous vessels than in other organs, mean that majority of brain cells lie within $25 \mu \mathrm{m}$ of a capillaries with nearly every neuron in the brain having its own capillary. However, it should be noted, that vascular density does differ between brain regions (e.g. gray vs. white matter) [21-23]. Third, the structure of arterial and arteriole vessels differs from other organs. Cerebral arteries have thinner vessel walls, with presence of internal elastic lamina in tunic intima and a multi-layered coat of smooth muscle cells (SMC) ( 20 layers in carotid artery) in large caliber artery to a single layer of circularly arranged and perpendicularly oriented to blood flow SMC in smaller arterioles, with essentially a zero-degree tone [21-23]. Similarly, cerebral veins are very thin walled, without valves and with SMCs only present in large veins. The stratified presence of SMCs along arterial and venous vessels is replaced by pericytes in the capillary bed, with a ratio of $1: 3$ to endothelial cells, taking in part the role of SMC [22, 24]. Fourth, the brain is perfused all the time and capillary flow is regulated by an intravascular pressure gradient between precapillary arteriole and post-capillary venule. The red cell velocity in brain capillaries is very high $(\sim 1 \mathrm{~mm} / \mathrm{s})$ and variable (range: 0.3 to $3.2 \mathrm{~mm} / \mathrm{s})$ allowing the effective oxygen transport to neuronal tissue to fulfil metabolic needs [25]. Fifth, the ratio of the number of descending arteries to the number of ascending veins is estimated to be 1.6. This ratio speaks to favor a system that rather feeds the tissues than drains [26]. Importantly, this ratio varies between species. Sixth, brain endothelial cells (BECs) show "zonation," as cellular phenotypic variations along the anatomical axis, with three specific endothelial clusters: venous BEC, capillary BEC and arterial $\mathrm{BEC}$ and a unique and biased distribution of arteriovenous markers [27].

A unique and specific component of the cerebrovascular network is the blood brain barrier (BBB). The BBB is a complex and highly specialized structural and biochemical barrier at the interface between blood and brain. It is intricately involved in regulating the entry of bloodborne molecules into brain and preserving ionic homeostasis within the brain microenvironment. Structurally, the BBB is composed of an interdependent network of brain capillary endothelial cells endowed with barrier properties, and adjacent perivascular cells, including astrocytes and pericytes that wrap the abluminal capillary surface and provide physical support and stability to the BBB $[28$, 29].

The perivascular milieu of the BBB also includes neurons and neuronal endings and extracellular matrix as well as transiently present macrophages/microglia. Together, these components form the NVU that mediates neurovascular coupling, modulates vessel tone and regulates regional cerebral blood flow. Thus, the dynamic and complex BBB/NVU is an essential structure for maintaining brain circulation and homeostasis (Fig. 2).

Mature endothelial cells of the BBB are characterized by tight junctions (TJs), multiple transporter systems, reduced cell thickness (37\% of other endothelial cells), a limited number of intracellular vesicles $(27 \%$ of other cells) and a close integration with brain parenchyma [30]. The BEC phenotype is also characterized by a gradual zonation with differences in gene expression profiles between ECs from capillaries: e.g. MFSD2a -essential 3 omega fatty acid transporter, from arterioles/arteries: 


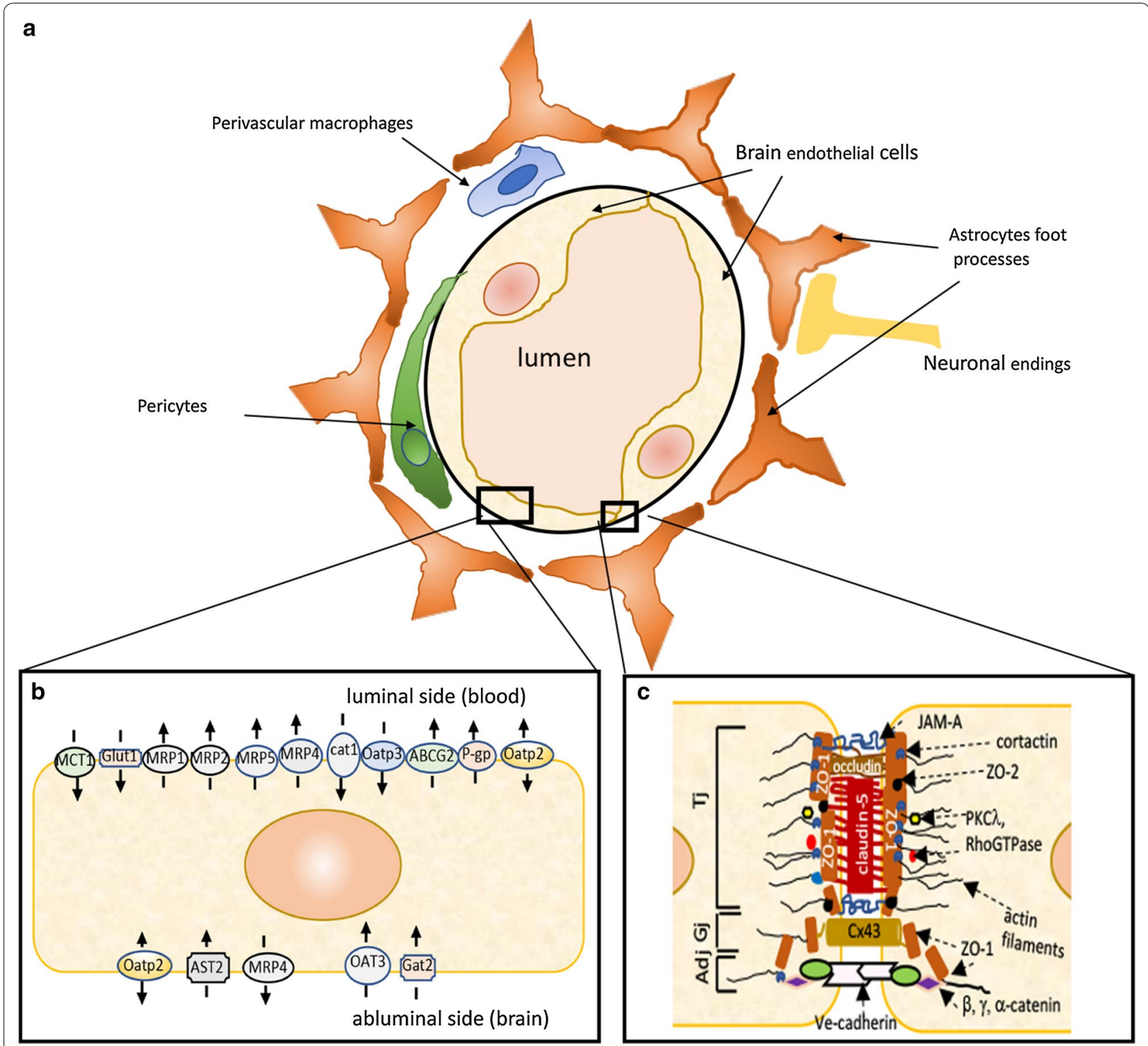

Fig. 2 Blood brain barrier (BBB) and neurovascular unit. a Schematic representation of cellular structure of BBB/NVU. b Brain endothelial cells have a wide range of transporters and carriers that build BBB influx (blood-brain) and BBB efflux (brain-blood) systems. c The BBB-endowed brain endothelial cells are characterized by a junctional complex that completely occludes the paracellular space and restricts paracellular movement from blood to brain. The junctional complex is composed from tight junctions (TJ), adherens junctions (AdJ) and gap junctions (GJ). These structures are generated by a complex network of protein-protein interactions between transmembrane proteins (e.g. claudin-5, occludin, junctional adhesion molecules [JAM], Ve-cadherin and Cx43) with scaffolding proteins (i.e. ZO-1) and the actin cytoskeletons

e.g. Bmx -non-receptor tyrosine kinase, Efnb2 (ephrin B2), Vegfc (vascular endothelial growth factor C), Sema3g (semaphorin 3G), and Gkn3 (gastrokine-3) and from venules/veins: e.g.Nr2f2 (nuclear receptor subfamily 2 group F member 2) and Slc38a5 (sodiumdependent amino acid transporter). BBB (capillary) ECs express a wide array of transporters reflecting the importance of BBB-associated trans-endothelial molecular transport [27].
In the capillary bed, the basal lamina of BECs is closely apposed to pericytes and astrocytic end-feet. As the BBB extends to precapillary arterioles and postcapillary venules, the astroglial end-feet are separated from the basal lamina with the vascular space known as the VirchowRobin space [31]. Both pericytes and astrocytes are considered as key elements for BBB features. Pericytes are often described as chemical sensors for communication between the endothelial cells and brain parenchymal 
cells, regulating cerebral blood flow, maintaining $\mathrm{BBB}$ integrity and controlling vasculogenesis, angiogenesis, neurovascular coupling and neuroinflammation [32]. In respect to vascular zonation, pericytes express a range of transporters, suggesting a role in regulating molecular transport at the BBB [27]. In addition, pericytes in close apposition to both BECs and neurons provide a mechanism for regulating blood flow. BECs and pericytes are linked via gap junctions, while pericytes and neurons communicate through transmitters such as adenosine triphosphate (ATP) and adenosine and their receptors [32].

Perivascular astrocytes are characterized by specific membrane domains on the astroglia surface, rich in intramembranous particles (OAPs). Their end-feet project on to blood vessels contacting the perivascular basal lamina (glia limitans superficialis et perivascularis) $[33,34]$. Astrocytic end-feet regulate the BBB properties of BECs (TJ assembly, permeability and recovery), pericyte localization and recruitment, regulate cerebral blood flow, angiogenesis, inflammation and metabolism. Astrocytic end-feet highly express aquaporin-4 (AQP4), a water channel, that is thought to be responsible for regulating water movement between intracellular, interstitial and vascular compartments, under the control of osmotic and hydrostatic pressure gradients [35-37].

Perivascular macrophages/microglia are a separate entity from other brain microglial cells although they share the same transcriptional program $[38,39]$. Their function is associated with regulating BBB inflammation, maintaining health of endothelial cells, BBB stability and integrity, regulating vasoconstriction and have role in role in angiogenesis and BBB recovery (TJ protein delivery) $[38,40,41]$. Finally, neurons/neuronal endings are an important component of the NVU. They lie approximately 8-20 $\mu \mathrm{m}$ from the brain endothelial cell basal membrane. Neurovascular coupling is mostly established via astrocytes or smooth muscle cells in precapillary arterioles $[42,43]$. Neurons play important roles in BBB development (Wnt and Sonic Hedgehog signaling pathways), regulating blood flow and microvascular permeability, interactions with the extracellular matrix, and stimulating angiogenesis [42-45].

The BBB is a physical barrier with a restrictive angioarchitecture that almost entirely blocks paracellular diffusion. This 'relocates' blood-brain exchange to the transcellular route. That can be via diffusion (lipophilic compounds), transporters or vesicular transport activity. One measure of BBB tightness is transendothelial electrical resistance (TEER), a measure of ionic permeability. For the BBB, the TEER is $\sim 1500-2000 \Omega \mathrm{cm}^{2}$ compared to $\sim 33 \Omega \mathrm{cm}^{2}$ for the peripheral vasculature, indicating a virtually impermeable BBB to ions [46]. The strict regulation of paracellular permeability at the $\mathrm{BBB}$ is due to a specific junction complex (tight, adherens and gap junctions) between the BECs, which resembles epithelial barriers rather than other (peripheral) endothelial cell barriers (Fig. 2c). In particular, this unique barrier property is defined by the TJs which are built of TJ protein strands.

The TJ complex is composed of three different classes of proteins: transmembrane, scaffolding proteins, and the actin cytoskeleton (Fig. 2c). The TJ transmembrane proteins include occludin, claudins and junctional adhesion molecules (JAM) -A, -B and -C [47-49]. Claudins, predominantly claudin-5, generate a strand-like structure on the cell lateral membrane and play the pivotal role in occluding the paracellular space and, thus, restricting paracellular permeability $[50,51]$. Another group of proteins (ZO-1, -2,- 3, Par-3, -6, afadin/Af6) form a structural scaffold that bring together transmembrane proteins, the cytoskeleton, and signaling molecules, clustering and anchoring transmembrane proteins in specific membrane domains and regulating $\mathrm{TJ}$ assembly and organization (cingulin, 7H6, Rab13, ZONAB, AP-1, PKC $\lambda$, heterotrimeric $\mathrm{G}$ protein) $[47,52,53]$. The cytoskeletal component of the TJ complex (actin filaments, non-muscular myosin, microtubules and actin binding proteins), produces a centripetal cell tension which may directly affect the adhesive property of TJs, and also play a critical role in mechano-sensing and mechano-transduction [54-56] (Fig. 2c).

Another part of the junctional complex that contributes to establishing the physical barrier is the adherens junction (AJ). It is built similarly to TJs with transmembrane proteins (Ve-cadherin), cytoplasmic/scaffolding proteins (p120, $\beta$-catenin and plakoglobin) and cytoskeleton components $[47,49]$. Brain endothelial barrier AJs have roles in barrier-genesis, regulating TJ complex formation, outin signaling processes and, in the mature phase, maintaining endothelial barrier permeability $[57,58]$.

Gap junctions (GJs) are a third part of the junctional complex. They are generated by the members of connexin (Cx) family. At the BBB, Cx expression varies between cells types. BECs express $\mathrm{Cx} 37, \mathrm{Cx} 40$ and $\mathrm{Cx} 43$, while pericytes and astrocytes express $\mathrm{Cx} 43$ and Cx30 [59-61]. Gap junctions are crucial in intercellular communication (i.e. exchange of ions, small molecules, miRNA), thus transducing signals between neighboring cells [60]. They have role in maintaining the physical barrier rather than directly contributing to that barrier [59] (Fig. 2c).

Since the restrictive angioarchitecture of the BBB blocks paracellular exchange of proteins, nutrients and waste products between blood and brain, BECs utilize a system of the transcellular vesicles, as well as carrier- and receptor-mediated transport systems for blood to brain 
and brain to blood exchange [62-64]. For transcellular transport, a vectorial movement of molecules within endocytic vesicles occurs across the cerebral endothelium, including vesicles associated with fluid phase endocytosis, adsorptive endocytosis and caveolae [64, 65]. It is very important to highlight that transcytosis is time-, concentration-and energy-dependent. BECs are recognized as cells with a low rate of transcytosis compared to other peripheral endothelial cells, although this is impacted by cerebrovascular disease [62].

The BBB is also endowed with selective and specific carrier-mediated transport systems. These systems regulate blood-to-brain transport (influx transport) and brain-to-blood transport (efflux transport). The influx transport systems carry essential nutrients, signaling molecules and occasionally drugs. Examples are, the transporters for glucose (GLUT1), amino acids $\left(\mathrm{Na}^{+}\right.$-independent neutral amino acid transporter, LAT1; SLC7A5 and 4F2hc; SLC3A2, basic amino acids transporters, CAT1; SCL7A2), nucleosides (CNT1; SCL28A1), prostaglandins, xenobiotics, valproic acid (Oatp2; SLCO1B1; SLC21A6), monocarboxylic acids (MCT1; SCL16A1) and creatine (CRT; SLC6A8) [66-73]. It is important to highlight that all of these transporters are potential candidates for enhancing drug delivery to brain (Fig. 2b).

A number of blood-brain efflux transporters clear small hydrophilic molecules generated in the brain, including those for neurotransmitters such as the norepinephrine transporter (NET), serotonin transporter (SERT), betaine/GABA transporter-1 (BGT1; SLC6A12), murine GABA transporter 2 (GAT2) and amino acid transporters (EAATs, ASCT2, ATA1, ATA2, ATA3), as well as neuromodulators, end-metabolites of neurotransmitters (i.e. OAT3 transports homovanillic acid), uremic toxins, and peptides [67, 74-77]. A separate group of efflux transporters are the ATP-binding cassette (ABC) efflux transporters. These are very important determinants of drug uptake into brain. Examples of this group of transporters are P-glycoprotein (P-gp/MDR1; ABCB1), breast cancer resistance protein (BCRP; $A B C G 2)$ and multidrug resistance-associated proteins (MRP; ABCC) 1, 4, 5, and 6 [78-82] (Fig. 2b).

BBB endothelial cells have many ion transporters and channels that regulate intracellular volume, $\mathrm{pH}$, and ion movement. These include $\mathrm{Na} / \mathrm{K}$ ATPase $(\mathrm{Na} / \mathrm{K}$ pump) present on the abluminal membrane, $\mathrm{Na}-\mathrm{K}$ $\mathrm{Cl}$ and $\mathrm{Na}-\mathrm{HCO}_{3}$ cotransporters, and $\mathrm{Na} / \mathrm{Ca}$ and $\mathrm{Cl} /$ $\mathrm{HCO}_{3}$ exchanger [83, 84]. Ion channels include an inward rectifier $K_{i r}$ channel, ATP-sensitive $K$ channels, L-type voltage-dependent $\mathrm{Ca}$ channels, a transient receptor potential C (TRPC) cation channel, a stretchactivated cation channel, and an inducible sulfonylurea receptor 1-regulated $\mathrm{Ca}$ - and ATP-sensitive cation chan-

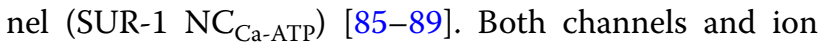
transporters are thought to be important in secreting brain interstitial fluid and regulating its composition.

\section{Cell culture models of BBB pathology in cerebrovascular diseases}

In vivo animal models can reproduce the pathological events in cerebrovascular disease in a complex setting. However, these preclinical studies, mostly done in rodent models, have limitations for both for determining mechanisms of injury and drug testing, and have not ultimately ensured successful clinical trials. The limitations are partially coming from species differences at the genomic (human vs. mouse difference is $10 \%, \sim 3000$ genes), and molecular (i.e. species-specific expression level of certain proteins) levels [90]. An example of this is in the response to inflammatory stimuli or cytotoxicity at the BBB in mice and human. Mice have a specific cytokines/ chemokines profile (i.e. CCL6, CCL9) after stroke that differs from the human chemokine response (i.e. IL8, CXCL7, CCL18) [91]. Such dissimilarities could affect the targeting/therapeutic strategies for stroke. Another example is a recent study on differences in gene expression between mouse and human BECs which identified a cluster of genes (e.g. periaxin) present in human but not mice [92]. This may directly affect the pathogenesis of cerebrovascular diseases as well limiting the successful modeling of stroke in animals. There are also interspecies differences in protein function, e.g. in the substrate affinity of different $\mathrm{ABC}$ transporters [93].

There is, therefore, an unmet need to develop adequate models to address mechanistic as well pharmacological questions related to cerebrovascular disease and other neurological conditions. One approach has been the development of humanized mouse models where human genes are expressed in mice. However, the effects of expressing human genes may be affected by complex species-specific gene and protein interactions limiting the full function of newly expressed proteins. Another direction is the development of adequate human in vitro models. This should be one priority as in vitro modeling of human cells is cost effective and may give more relevant information.

In vitro models have several important advantages: (a) they have a tightly controlled environment with reproducible conditions, (b) they allow detailed mechanistic analyses, (c) they can accelerate pharmaceutical procedures, and (d) they limit ethical constraints and require no expensive and time-consuming ethical approval procedures. The major question over in vitro models is how well they exactly mimic the complexity of $\mathrm{BBB}$ in vivo. Over the last two decades, there have been major 
attempts to develop better BBB/NVU model systems which resemble the interactions between cells/components of the BBB and have in vivo barrier characteristics. The currently available in vitro models to study BBB pathology in cerebrovascular disease are summarized in Fig. 3, and their properties and utilization in setting of cerebrovascular disease are discussed in the following sections.

\section{Overview of BBB in vitro models}

$\mathrm{BBB} / \mathrm{NVU}$ models can be divided into ones that enable study of isolated components of the $\mathrm{BBB}$, such as $\mathrm{BEC}$ monolayers, and those seeking to replicate the more complex composition of the $\mathrm{BBB} / \mathrm{NVU}$, such as coculture in Transwells (2-D systems), and to truly mimic the mutual communication between cells with/without blood flow in 3D systems.

The pivotal component in building any $\mathrm{BBB} / \mathrm{NVU}$ in vitro model is the type of cells used. Primary cells in culture have the benefit of partially keeping their own phenotype. Primary BECs have the ability to establish good BBB physical properties (TEER 150-400 $\Omega \mathrm{cm}^{2}$ ) and other BBB functions (e.g. transporter expression) [94-97]. Primary glial cell cultures also resemble the molecular properties and differentiation of these cells in vivo. However, primary cell isolation and purification is time-consuming with limited yields. Culturing conditions can change transcriptional activity and limit establishment of the in vivo phenotype [98]. In addition, possible contamination with other cell types can affect reproducibility. It is also important to highlight that primary cells can lose phenotypic identity with increased passage number, limiting their application.

Immortalized cell lines are often used for in vitro BBB modeling. The most utilized cell lines used for BECs are TY08, HMEC-1 and HCMEC/D3; for astrocytes, A735 and C6; for microglial cells, HMO6; and pericytes, HBPC/ci37 [99-105]. Cells can also be isolated from tumors like teratoma (NT2 cell line, for deriving neurons and oligodendrocytes) or neuroblastoma (SH-SY5Y neuronal cell line) [106, 107]. Immortalized cells have major advantages including a high proliferation rate and a constant phenotype during passaging. However, these cells have variations in phenotype and morphology. For example, in BECs (i.e. HCMEC/D3), this is reflected in low protein expression of junction proteins, adhesion molecules enzymes and transporters. This cannot be corrected by supplementing culture media (e.g. $\mathrm{LiCl}$ to activate $\mathrm{Wnt} / \beta$-catenin signaling) or coculturing with astrocytes and pericytes to achieve tightness. However, there are still limitations in achieving barrier properties although transporter density and function is preserved [108]. Despite that, because of their high proliferation rate and constant phenotype,

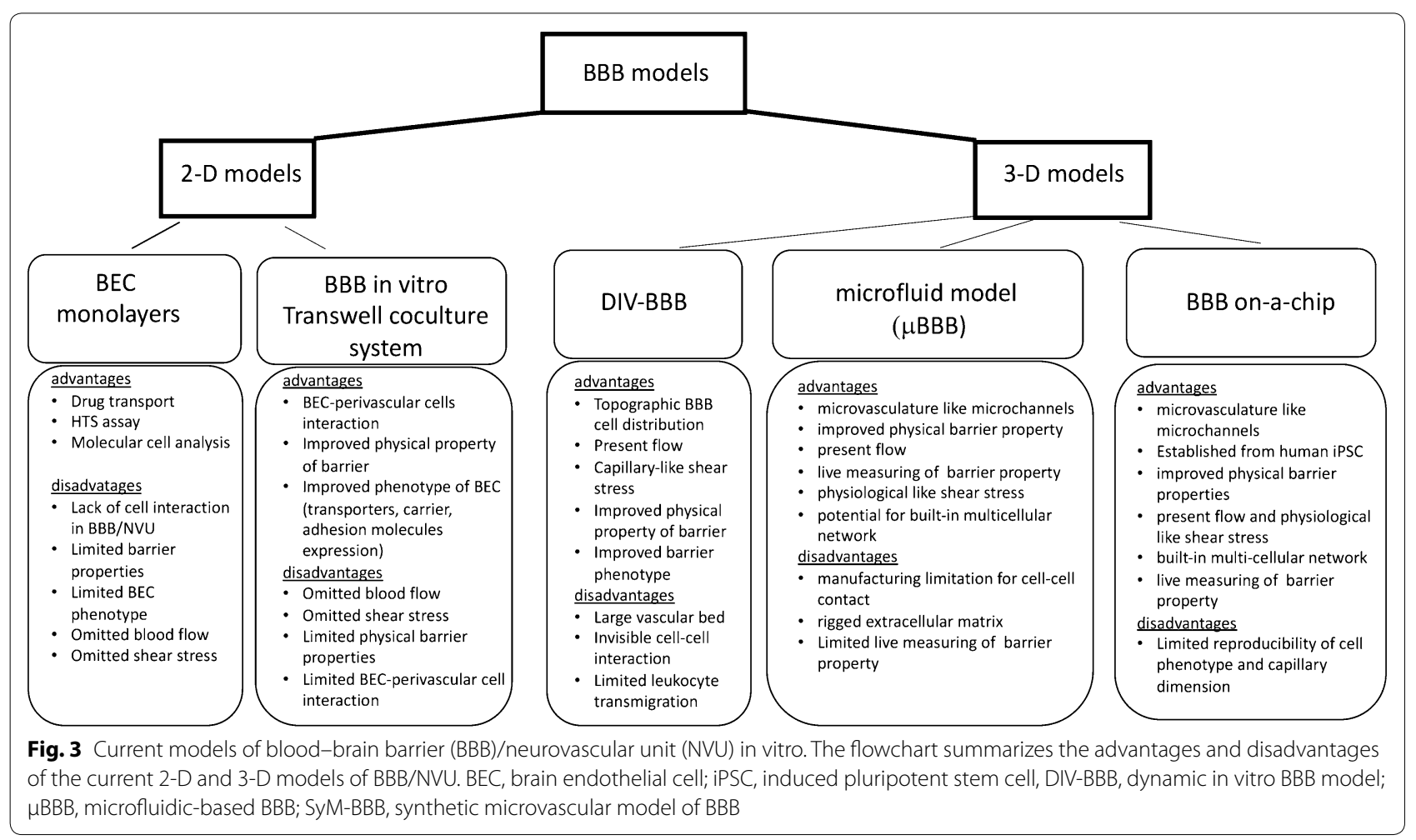


these cell lines are often used for high throughput screening.

An attractive alternative is to derive human BECs and other cells of the NVU from inducible pluripotent stem cells (iPSCs). This new technology is based on reprogramming somatic cells (i.e. fibroblasts or $\mathrm{T}$ cells) by ectopic expression of OCT4 (POU5F1), SOX2, KLF4 a nd c-MYC that preserves the epigenetic and transcriptional memory of the in situ cells [109]. These cells have a high proliferative index that is not dependent on oncogenic factors (e.g. unlike immortalized cells) and preserve the phenotype of somatic cells. The most efficient method for generating iPSC is based on retrovirus- or transposon-mediated gene transfer (Cre-loxP or PiggyBac transposition) [110]. Currently, advances in iPSC technologies have reduced phenotypic variations among iPSC clones and enabled derivation of cells from somatic cells or postmortem tissue [111]. A disadvantage of iPSCs is a close link with cell cycle and division status that may directly affect the reprogramming and overall efficiency, as well a limitation in the establishing brain endothelial phenotype.

In considering in vitro BBB modeling, it is important to note that recent findings have shown arterial-capillary-venous zonation and regional heterogeneity in BEC and perivascular cell phenotype [27]. Although that data is still mostly from animals, a better characterization of human BECs from different caliber vessels could bring new insights into cerebrovascular physiology and pathology. In vitro, it may, therefore, be important to try and model such zonation/regional heterogeneity. It is also important to recognize that such zonation/regional heterogeneity may lead to variations in results between laboratories which may derive different BEC populations using specific isolation procedures.

Currently, BEC monolayers are widely used and are a simplistic model for studying endothelial-based pathology or drug transport. BECs monolayers suffer from several disadvantages: low TEER $\left(\sim 150 \Omega \mathrm{cm}^{2}\right)$, high paracellular permeability due to the absence of perivascular cells to stabilize the barrier, incomplete junction complex establishment, inadequate transporter localization and expression, and often an "edge effect" as the cells have difficulty adhering to the side of culture dishes [95, 101, 112]. Although this model lacks the cellular interactions that exist in vivo (i.e. with perivascular cells) and other important physiologically important factors, such as shear stress, it is still compatible with high-throughput screening (HTS) assay, and useful for dissecting endothelial cellular and molecular events and drug transport.

Co-cultures, also known as 2-D BBB models, include double (BEC-astrocyte, BEC-pericyte, BEC-neuron, BEC-microglia) and triple (BEC-astrocyte-pericyte) cultures formed in the Transwell dual chamber system [97, 113-118]. The BEC are seeded on the membrane in the upper chamber while perivascular cells are cultured either on the other side of membrane or on the bottom of the lower chamber. In vivo BBB properties are partially mimicked, with higher TEER $\left(\sim 450-1300 \Omega \mathrm{cm}^{2}\right)$, lower permeability coefficients and better transporter expression (e.g. GLUT-1, P-gp, MRP, BCRP) than BEC monolayers due to close interaction with perivascular cells [113, 115, 118-122]. These models, particularly triple co-culture models, are based on the ability of astrocytes and pericytes, to induce BBB properties $[119,123]$. Lack of blood flow and shear stress, pivotal components for establishing vascular cytoarchitecture, are disadvantages of the 2D models. Other important limitations are an inability to address all aspects of NVU simultaneously. Thus, 2-D models are utilized to understand the role of a specific factor rather than the interaction of cell types that work together to coordinate blood flow or permeability.

Addition of flow and physiological shear stress ( 5 dyne $/ \mathrm{cm}^{2}$ ) to BEC monolayers in a parallel plate flow chamber (PPFC) is a step forward for building 3-D BBB models. The PPFC platform consists of a polycarbonate chamber which mimic the lumen of blood vessels and BECs plated on the glass coverslip [124, 125]. The culture media flow from one side to other in a flow chamber. The PPFC platform is widely used in vascular biology to study leukocyte-endothelial cell interaction, tumor-endothelial cell interaction, cellular chemotaxis, endothelial cells and drug resorption [125]. The major limitation is an inability to form perivascular cell-BEC interaction and reproduce BBB complexity.

An important step forward in modeling the $\mathrm{BBB}$ are 3-D models. The basic principle is to establish the $\mathrm{BBB}$ in artificial microvessels, achieved by growing $\mathrm{BEC}$ in the lumen of coated channels to form a microstructure with inclusion of perivascular cells (astrocytes, pericytes) on the outer side of the channels. The 3D platforms (BBB -on-a-chip) are broadly categorized into three groups: [1] dynamic in vitro BBB model (DIV-BBB), [2] microfluidic $\mathrm{BBB}(\mu \mathrm{BBB})$ [3] BBB-on-a-chip.

DIV-BBB was one of the first 3-D platforms generated to mimic the complexity of the BBB. The BECs are cultured on the luminal side of artificial capillaries (microporous pronectin-coated polypropylene hollow fibers), while glial cells are seeded on the outer surface [126-128]. An advantage of the model is the topographic distribution of cellular component of BBB that reassembles the BBB in vivo. The platform also has flow levels and intraluminal pressure $\left(5-23\right.$ dyne $\left./ \mathrm{cm}^{2}\right)$ comparable to that occurring physiologically in capillaries $[126,127]$. Compared to the Transwell static model, barrier properties are more similar to those in vivo (high TEER, cell 
polarization and transporter expression) and the preparation is viable for up to several months. Disadvantages include the presence of a thick basal membrane (hollow fiber wall, $\sim 150 \mu \mathrm{m}$ ), difficulties in easily observing cellcell interaction, as well as limitations for studying drug transport or leukocyte transmigration due to the artificial microvessel pore sizes [128].

Microfluidic 3-D BBB ( $\mu \mathrm{BBB})$ models are formed on the platform of BBB-DIV and represent a flow chamber with built-in $\mathrm{Ag} / \mathrm{AgCl}$ electrodes for measuring TEER [129-131]. Generally, this system is composed from porous membrane segments (mostly polydimethylsiloxane (PDMS)-based systems) that form sandwich structures on the chip. There are two channels, vascular (one side of membrane) seeded with BEC and a parenchymal side, filled with hydrogel and seeded with perivascular cells (e.g. astrocytes or pericytes) aligned horizontally or vertically [129-131]. In the horizontally aligned microfluidics vasculature model, horizontally positioned apical and basolateral sides are divided by micropillars with a $3 \mu \mathrm{m}$ gap. Some modifications include a centrally located tissue chamber field with hydrogel for perivascular cells. This system has pulsed flow, facilitating the stretchinduced transport and retrograde transport of high molecular weight dextran [132, 133]. A modified version is the vertically-aligned $\mu \mathrm{BBB}$ model that contains two perpendicular flow channels, with two TEER electrodes and a relatively thin $10 \mu \mathrm{m}$ culture membrane that allows interaction with perivascular cells (e.g. astrocytes [134]. Dynamic vertically-aligned $\mu$ BBB models achieve TEER values of $>250 \Omega \mathrm{cm}^{2}$, have a flow capability with physiologically relevant shear stress of 5.8 dyne/ $\mathrm{cm}^{2}[129,131$, 134].

More complex microfluid platforms include NVU on a chip, with more possibility for multicell culturing [135, 136]. The major advantages of the system are the microchannel size, which is similar to microvascular structures, better fluid control and the possibility to build multicellular networks on the chip. This platform has several limitations that span from excluding the use shear stress and TEER measurement in some models, the presence of the porous membrane that limits cell-cell interaction at BBB, and a rigid extracellular matrix that affects perivascular cell organization and viability. One of the modification of $\mu \mathrm{BBB}$ is a synthetic microvasculature model of the BBB (SyM BBB), which is composed of microchannels partitioned into two side-by-side chambers by using pillars or posts that mimic the $3 \mu \mathrm{m}$ membranes from Transwell systems [137]. The platform has adjacent apical and basolateral channels in the same horizontal plane, with flow capability on apical and basolateral sides. An advantage of the system is a more realistic microcirculation environment including mechanobiological measurement, presence of fluid flow and shear stress, an oxygen permeable substrate and real time monitoring. A disadvantage is a limitation in measuring TEER due to the design where the channels are connected at $50 \mu \mathrm{m}$ length which is far larger than barrier between cells in the Transwell system.

In recent years, progress has been made in developing 'organs-on-a-chip' systems. This is a small microfluidic system that share characteristics of $\mu \mathrm{BBB}$ and SyM-BBB. BBB-on-chip platforms contain two PDMS layers that hold electrodes (for TEER measurement) and are separated by a $10 \mu \mathrm{m}$ thick polycarbonate membrane containing $0.4 \mu \mathrm{m}$ pores $[138,139]$. Two channels have flow capabilities and run perpendicular to each other with a cross sectional area of $0.25 \mathrm{~mm}^{2}$. This system can achieve physiological relevant shear stresses of 5.8 dynes $/ \mathrm{cm}^{2}$ and uses micro-patterned devices for cell culture, has improved optical clarity, and can measure TEER simultaneously [138, 139]. By incorporating patient-derived iPSCs, BBB-on-chip is able to recapitulate the complex tissue architecture and the physio-chemical microenvironment of human $\mathrm{BBB}$ and facilitate predictive personalized medicine applications [140-143]. The major advantage of this technology is establishing tissue architecture at the micro- and nano-levels. Barrier resistances of up to $4000 \Omega \mathrm{cm}^{2}$ occur, recapitulating BBB TEERs in vivo, and incorporation of iPSCs enables the effects of patient-specific mutations to be studied [140, 142, 143]. Some disadvantages of this approach are shared with $\mu B B B$ and SyM-BBB. In addition, this model still suffers from an inability to reproduce capillary dimensions and to recapitulate the hierarchical branching of in vivo structures. Still such models represent an important base for modeling BBB complexity, which could have major near future impact.

How are these models beneficial and applicable to studying physiological and pathological responses at the BBB? With all the limitations in mimicking complex BBB biology, these models still provide highly controlled systems to dissect, reproduce and characterize the complexity of the BBB. BBB models can be applied to translational, pharmacological and mechanistic studies. 2-D models are cost effective and reproducible platforms for performing cell migration and drug transport assays [144]. DIV-BBB provides a solid base for understanding the effects of shear stress on BECs in different pathological conditions [144]. 3-D models ( $\mu$ BBB, BBB-on-chip) are potential tools in pharmacology (drug uptake, dosing, drug discovery), disease target research and translational medicine [145]. In particular, using patient-derived iPSCs in "BBB-on-chip," as well inclusion of the blood flow on the luminal side, is a promising tool for understanding disease mechanism and drug testing [146]. 


\section{Modeling the BBB pathology of cerebrovascular disease}

The BBB and NVU play an active role in causing and/or responding to cerebrovascular diseases. The pathogenesis of cerebrovascular disease is complex with a wide spectrum of interconnected pathological processes. However, the effects at the BBB can be broadly classified as: (a) cytotoxic effects, (b) metabolic changes, (c) inflammation and (d) aging processes. These processes are reflected in $B B B$ function, e.g. diminished BBB integrity (from lowlevel $\mathrm{BBB}$ leakage to $\mathrm{BBB}$ breakdown), inflammatory remodeling of the $\mathrm{BBB} / \mathrm{NVU}$, diminished recovery/angiogenesis and alterations in BBB transport systems. Inherited diseases, such as CCMs and CADASIL, also impact the $\mathrm{BBB}$ with the gene mutations affecting different signaling pathways.

Dependent on the disease state, different segments of the cerebral circulation may be impacted. For example, atherosclerosis predominately occurs in large arteries, while aging is associated with small vessel disease and vascular dementia. However, the microcirculation (arterioles, capillaries and venules) is also important for disease processes and is a primary site of dysfunction in most cerebrovascular diseases. Thus, this review will now mostly focus on the pathology and modeling of cerebrovascular disease at the level of the $\mathrm{BBB} / \mathrm{NVU}$ and particularly review human BBB systems.

\section{Stroke injury modeling}

In vivo, ischemic stroke may either be due to a permanent occlusion of blood vessels or a transient occlusion. The latter may be due to spontaneous reperfusion (restoration of blood flow) such as occurs in TIAs but which can also happen later in other strokes. Restoration of blood flow can also occur after administration of tissue plasminogen activator or thrombectomy, the two current therapeutic options for ischemic stroke [2].

The $\mathrm{BBB} / \mathrm{NVU}$ is impacted by and actively involved in ischemic core (infarct) formation in the acute phase and in the progression and resolution of injury in the subacute and chronic phases. In the acute phase, ischemia initially induces a vasodilatory response to try and maintain blood flow (i.e. by increasing flow through the collateral circulation 'bypassing' the occluded vessel). However, within areas of injury, there can be vasoconstriction that can cause capillary occlusion even after reperfusion (noreflow phenomenon) regulated by pericytes [147]. In addition, there are cytotoxic effects on BECs with mitochondrial dysfunction and altered ion channel and transporter activity (e.g. $\mathrm{Na}^{+}-\mathrm{K}^{+}-\mathrm{Cl}^{-}$cotransporter and $\mathrm{Na}^{+}$/ $\mathrm{H}^{+}$exchanger) $[84,148,149]$. Similarly, in astrocytes there is energy depletion, diminished astrocyte maintenance of glutamate homeostasis, increased intracellular
$\mathrm{Ca}^{2+}$ accumulation and AQP4 channel activation that can lead to cell swelling and cell death as well as initiating a cascade of events that impact the BBB and NVU later in ischemia [150, 151].

The subacute phase is associated with a cascade of events that changes BECs to a prothrombotic and proinflammatory phenotype. This includes increases in protease-activated receptor 1 , tissue factor and matrix metalloproteinases (MMPs), and an upregulation of endothelial adhesive molecules (ICAM, VCAM, P- and E selectins) [152, 153]. There is an astrocyte-, pericyteand microglial cell-guided inflammatory response mirrored in upregulation of cytokines/chemokines (IL1 $\beta$, TNF- $\alpha$, IL6, IL15, CCL2, CXCL1, CXCL10, CXCL12), proinflammatory associated small molecules (e.g. S100, $\mathrm{Ca}^{2+}$-binding protein $\mathrm{B}$; $\left.\mathrm{S} 100 \mathrm{~B}\right)$ and nitric oxide $(\mathrm{NO})$ [152-154]. BBB integrity is diminished with TJ alterations and increased vesicular trafficking. These changes result in leukocyte infiltration, vasogenic brain edema and potentially hemorrhagic transformation.

The chronic phase after ischemic stroke is characterized by reestablishment of BBB integrity (TJ resealing; although this may be incomplete), remodeling of the vascular network, removal of damaged cells and scar formation [155]. There is also angiogenesis, but this is often incomplete. It should be noted that the degree of angiogenesis correlates with outcome in stroke patients.

How are these events modeled in vitro? In most in vitro studies of the BBB/NVU, the focus is on one or more pathogenic events, like ischemia, inflammation, and cytotoxicity, and answering specific hypothesis driven questions. Despite all the limitations of specific in vitro models, such studies yield very important data regarding the stepwise cellular and molecular events during ischemic injury and suggest new targets for treating ischemic BBB injury. Some characteristics of the in vitro stroke models are presented in Table 1, and are discussed below.

In vitro 'ischemic' injury at the $\mathrm{BBB}$ is mimicked by one of two methods: chemical/enzymatic interference with cellular oxidative metabolism or depriving cells of oxygen and glucose. The chemical methods involve inhibiting the mitochondrial electron transport chain by treating cells with rotenone, antimycin and sodium azide [156, 157]. The enzymatic methods are based on manipulating the glucose oxidase and catalase (GOX/CAT) system and 2-deoxyglucose [158]. Both methods cause fast ischemic injury and have good reproducibility, particularly antimycin [156]. Oxygen-glucose-deprivation (OGD) is the most commonly used model for in vitro 'ischemic type' of injury and mimics conditions induced by obstruction of blood flow [159]. The model is based on exposing cells to $\mathrm{N}_{2} / \mathrm{CO}_{2}$ equilibrated medium without glucose 
Table 1 Modeling cerebrovascular disease (CVD) in culture. Summary of current in vitro models of CVD that include the modeled in vitro condition, blood brain barrier (BBB) pathology and utilized in vitro BBB model

\begin{tabular}{|c|c|c|c|c|}
\hline CVD & In vitro model condition & BBB pathology & Utilized in vitro BBB model & Refs. \\
\hline \multicolumn{5}{|l|}{ Stroke } \\
\hline Ischemic & $\begin{array}{l}\text { OGD (1-5 h) } \\
\text { OGD + Reperfusion (reoxygena- } \\
\text { tion + normal glucose level) } \\
(1-5 \text { h }+1-96 \text { h) } \\
\text { Chemical ischemia (rotenone, } \\
\text { antimycin and sodium azide) } \\
\text { Enzymatic (GOX, GOX/CAT and } \\
\text { 2-deoxyglucose) }\end{array}$ & $\begin{array}{l}\text { Hyperpermeability } \\
\text { Cytotoxicity } \\
\text { Inflammation } \\
\text { BBB recovery } \\
\text { Angiogenesis }\end{array}$ & $\begin{array}{l}\text { BEC monolayer } \\
\text { 2-D model } \\
\text { DIV-BBB } \\
\text { 3-D model }\end{array}$ & $\begin{array}{l}{[78,127,148,160,162,165]} \\
{[164,166,167,182]} \\
{[126]} \\
{[135]} \\
{[156-158]}\end{array}$ \\
\hline Hemorrhagic & $\begin{array}{l}\text { hemin/hemoglobin +/OGD } \\
\text { thrombin } \pm \text { OGD }\end{array}$ & $\begin{array}{l}\text { Hyperpermeability } \\
\text { Cytotoxicity } \\
\text { Inflammation }\end{array}$ & $\begin{array}{l}\text { BEC monolayer } \\
\text { 2-D model }\end{array}$ & $\begin{array}{l}{[187,189,207-211]} \\
{[186]}\end{array}$ \\
\hline \multicolumn{5}{|c|}{ Vascular dementia } \\
\hline CADASIL & $\begin{array}{l}\text { Replicative senescence } \\
\mathrm{H}_{2} \mathrm{O}_{2}(50 \mu \mathrm{M}) \\
\text { modification of telomerase } \\
\text { DNA damage } \\
\text { NOTCH3 mutation }\end{array}$ & $\begin{array}{l}\text { Senescence } \\
\text { Hyperpermeability } \\
\text { Inflammation }\end{array}$ & $\begin{array}{l}\text { BEC monolayer } \\
\text { hiPSC }\end{array}$ & $\begin{array}{l}{[194,201,202]} \\
{[206]}\end{array}$ \\
\hline \multicolumn{5}{|c|}{ Vascular malformation } \\
\hline CCM 1-3 & Gene silencing & Hyperpermeability signaling & BEC monolayer & {$[59,95]$} \\
\hline
\end{tabular}

BEC brain endothelial cell, CAT catalase, CCM cerebral cavernous malformation, GOX glucose oxidase, hiPSC human induced pluripotent stem cell, OGD oxygen glucose deprivation

and maintaining cells in a hypoxic/anoxic chamber. The time may vary from 1 to $5 \mathrm{~h}$, with the degree of the injury increasing with time. To mimic reperfusion injury, cells are returned to normoxic and normalized glucose conditions. Similar to OGD, the degree of injury after reperfusion varies with time of the exposure of cells to normoxia and normalized glucose level. This experimental setting has been applied in numerus studies with 2-D BBB models in both monocultures of BECs and dual and triple co-cultures of murine and human primary and immortalized cell lines [96, 159-168]. However, in addition to reducing oxygen and glucose delivery, stroke in vivo also reduces blood flow and thereby endothelial shear stress. This can also impact BBB integrity. In a recent study utilizing the DIV-BBB model, this was taken into consideration and the OGD condition induced by injection of ischemic media $\left(\mathrm{N}_{2}, \mathrm{CO}_{2}\right.$, no glucose) was accompanied by reduced shear stress and blood flow for $1 \mathrm{~h}$ to better mimic in vivo stroke [126]. Reperfusion injury was initiated with reperfusion media (normal oxygen and high glucose) with a normal shear stress [126].

The effects of OGD have been examined in the 3-D BBB model system (6 h OGD followed by reperfusion), although without shear stress and flow, giving new perspectives on the sequence of events and cell-cell interactions in microfluidic (capillary)-like settings [135]. There are still no studies regarding ischemic injury in the $\mu \mathrm{BBB}$ model, although the $\mu \mathrm{BBB}$ is currently utilized to investigate the hemodynamic effect of thrombosis and microvascular occlusion in hematological diseases (i.e. Sickle cell disease) [125].

Although OGD can cause 'ischemic' injury, with or without 'reperfusion', there are several caveats to the model [169]. Oxygen is a key component for cell function and cells in vitro are normally cultured at $21 \% \mathrm{O}_{2}$, the content of air. This percentage is much greater than that present in vivo (arterial blood 10.5-13\%, organs 2-8\%). Thus, in vitro-conditioned cells are in a hyper-oxygenated state that may affect cellular responses to ischemia and generate cells resistant to oxidative stress [170]. Another issue is the glucose level in equilibrium media. Cell culture media often has a glucose level of $>20 \mathrm{mM}$, while glucose levels in plasma and brain are 5.5-7.8 and 0.82$2.4 \mathrm{mM}$, respectively. Long term hyperglycemia may negatively affect cell viability and influence AMPK signaling [171]. Therefore, adjustment of glucose level in normoxic condition is essential for producing the relevant cellular response under diseases conditions. Another problem relates to the type of model, particularly to static 2-D models of BBB. Due to the absence of flow and low exchange of media, BEC have high glucose consumption and lactate production [128]. This may switch the cellular metabolism to anaerobic metabolic pathways in preexperimental conditions and affect BEC phenotype and response to ischemic injury.

What components of stroke-induced BBB dysfunction are mimicked using in vitro BBB models? Ischemia/ reperfusion (I/R) injury in vitro mirrors the events and 
signs associated with deteriorations in $\mathrm{BBB}$ integrity. Thus, there is hyperpermeability, inflammation, focal excitotoxicity/cytotoxicity and alterations in transporter expression and function. The degree of diminished BBB integrity can be evaluated by measuring TEER and/or tracer permeability (ranging from small to high molecular weight) at different time points of OGD and reperfusion [96, 160, 163, 168, 172]. TEER assesses ionic permeability and it has limitations in defining the degree of BBB hyperpermeability. However, it is a good indicator of $\mathrm{TJ}$ status and paracellular permeability. In vitro tracer permeability assays represent a sensitive index of barrier properties. Tracers used to evaluate permeability in vitro are divided into two groups: a) non-cell permeable/ non-transported tracers (e.g. mannitol, sucrose, dextran and inulin) can be used to evaluate paracellular permeability, and b) tracers which undergo receptor binding and vesicular transport or are transported by influx or efflux transporters (e.g. albumin, propranolol and rhodamine-123) to assess transcellular permeability. The same type of tracers can be used in static 2-D models, as well in DIV-BBB and 3-D models [96, 126, 135, 172]. Tracer permeabilities not only qualitatively evaluate $\mathrm{BBB}$ integrity but, taking into consideration time as a parameter and calculating the permeability coefficient $\mathrm{P}_{\mathrm{app}}$, quantitively evaluate the magnitude of $\mathrm{BBB}$ hyperpermeability. This functional assay in combination with $\mathrm{TJ}$ protein expression/localization and vesicular activity is useful and relevant to evaluate vascular integrity related to $\mathrm{BBB}$ function after I/R injury [95, 96, 168, 172]. There are several important points to be taken into consideration regarding BBB permeability assessment: (a) permeability changes can vary with conditions of OGD severity under different culturing conditions, (b) BEC are particularly prone to ischemic injury and utilizing cell lines, primary cell cultures or IPSCs may change the BBB response in both in the magnitude and the timing of BBB "opening", and (c) in evaluating vascular permeability in BBB-DIV and 3-D BBB models, it should be take into consideration that tracer concentration, flow rate and pressure between two compartments may affect vascular permeability measurements.

Inflammation is a driving force in BBB injury/breakdown after ischemic stroke, as well as in functional recovery. While most in vitro stroke models are focused on the brain parenchymal cell response (e.g. astrocytes) and evaluation of BBB breakdown, in vivo circulating inflammatory cells, leukocytes, also have an important contribution. There are a number of systems in which leukocyte recruitment can be assessed: from static transmigration assays through membranes, to static or flowbased leukocyte-BEC interaction assays [135, 172, 173]. However, few have utilized these assays to investigate stroke-specific leukocyte recruitment. In 2-D models, leukocyte transmigration is measured by adhesion assay or direct chemotactic assay in Transwell systems [172]. For both types of assay, after exposure of 2-D models to OGD condition and reperfusion, isolated neutrophils and/or monocytes are layered on the BECs on the insert and adhesion and/or cell transmigration is evaluated over time. A simplified version of the in vitro poststroke-inflammatory response is exposure of 2-D models of BBB to inflammatory cytokines, important hallmarks of this type of inflammation $[135,173]$. This model yields important information regarding the leukocyte-BEC interaction and leukocyte adhesion in post-stroke conditions, although the migration results may be questionable due to effect of gravity on cell migration. An advance in modeling the post-stroke inflammatory response is using the DIV-BBB model. In this model, leukocytes can be introduced in the reperfusion media to assess leukocyteBEC interactions [126]. Advantages include the phenotype and physical organization of the barrier resembling in vivo conditions. However, the model is still limited by the absence of leukocyte transmigration due to the technical/fabrication constraints of model. Similar advantages and limitations apply to current 3-D BBB models, although progress is being made in fabrication that may overcome this. Important knowledge has been generated using in vitro models, particularly in relation to the contribution of inflammation in BBB breakdown poststroke and the mechanisms of BBB biphasic opening after stroke.

A third mechanism of BBB injury modeled in vitro is cytotoxicity/excitotoxicity. Endothelial cell death (apoptosis, lysosome-dependent necroptosis) does occur during cerebral ischemia and cytotoxic mechanisms and potential therapies can be studied in vitro with OGD [174]. Similarly, the generation of reactive oxygen species and related cell injury that occurs during reperfusion is mimicked during the 'reperfusion' phase after OGD. Excitotoxicity in ischemic stroke is mostly studied through the application of glutamate receptor agonists such as $\mathrm{N}$-methyl-D-aspartate (NMDA) or high levels of glutamate $(\sim 3 \mathrm{mM})$ or relevant antagonists [175]. Although it is established that BEC are resistant to the L-glutamate-induced toxicity, BECs play a very important role in regulating brain glutamate. There are also several recent studies pinpointing that BEC can be affected by excitotoxic mechanisms in vitro (exposure to high level of L-glutamate) which trigger NMDA receptor activation, $\mathrm{Ca}^{2+}$ elevation and reactive oxygen species production [175].

The processes involved in BBB recovery after stroke are also being modeled in vitro. Most of the studies have examined BEC monocultures or 2-D BBB models 
exposed to OGD/reperfusion or treated with specific cytokines/growth factors involved in recovery $[176,177]$. Although BEC monocultures are a poor model to investigate $\mathrm{BBB}$ recovery, they are still broadly used to analyze signaling processes involved in BBB repair. On the other hand, 2-D BBB models provide essential facts regarding the role perivascular cells in barrier post-stroke recovery as well as analysis of cell signaling. Cocultures of BEC and astrocytes or BEC and pericytes are often used [178, 179]. One recently developed model is co-culture of neuronal stem cells and BEC forming vasculature-like structures. This provides a more complex model to investigate recovery processes at the BBB and NSC-induced neovascularization. This coculture highlights the importance of a complex interplay between NSCs and BEC as well as juxtacrine and autocrine/paracrine factors involved in BBB morphogenesis [180]. Modeling of the BBB poststroke recovery processes in vitro has caveats and limitations. Besides ones related to the manufacturing-related limitation of BBB models, a significant caveat is the type of the cells that are used in modeling and their capacity for recovery after OGD/reperfusion injury.

Ischemia also alters transporter expression/activity (i.e. Glut1, Sglt1, Oatp2) that may lead to BBB metabolic dysfunction. In addition, some transporters are involved in the in the brain uptake of potential therapeutics [181, 182]. For example, Oatp1a4 is involved in transporting opioid peptides (2,5-Pen-enkephalin and deltorphin II) as well atorvastatin, a drug used in neuroprotection [181]. Alterations in transporters expression/activity could significantly impact drug uptake and attenuate the benefits of therapeutic strategies to reduce stroke injury.

Currently, a wide range of models are used to examine the effects of ischemia on the $\mathrm{BBB} / \mathrm{NVU}$ in vitro. A major decision in such studies is the extent to which investigators try and replicate the 'whole' of ischemia (e.g. having models with flow that can be stopped) or just particular facets (e.g. hypoxia or inflammation). The former has the advantage of better replicating events occurring in vivo and examining multiple injury pathways that may interact. The latter has the advantage of relative simplicity and of examining in detail one particular pathway. The same considerations apply to whether co-cultures or BEC monocultures are used. Whichever models are used, the deficiencies in the models should be acknowledged and discussed.

What are the future directions for modeling ischemiainduced BBB injury? Further developing 'BBB-on-a-chip' is one key for in vitro stroke modeling. Developing $B B B$ models that exhibit physiologically relevant levels of human BBB function for at least 1 week in vitro are critical, including low barrier permeability and expression of multiple efflux pumps and transporter functions required for analysis of ischemic BBB/NVU injury as well of drug and therapeutic transport for stroke injury treatment. Furthermore, modeling the stroke injury in BBB-on-achip could bridge some obstacles with regards to cell response. Using iPSCs has great advantages, even though stroke is often not associated with a specific genetic profile. This model should provide opportunities to use cells from the same donor or donors with the same condition and to exclude cells from healthy donors. Mixing cells may cause obstacles in research and 'all-human' systems should be promoted for modeling cerebrovascular diseases. This should give benefits in a better understanding of cell response and the degree of those responses.

\section{Modeling of BBB injury in hemorrhagic stroke}

Hemorrhagic stroke is initially a cerebrovascular event with rupture of a cerebral blood vessel, but there is also secondary BBB damage. The BBB injury, including hyperpermeability, may be the consequence of the mass effect (hematoma with increased intracranial pressure and reduced blood flow) [183]. However, factors derived from the hematoma (thrombin, fibrin and components of erythrocyte lysate, including hemoglobin and iron) are also involved [183]. For example, such factors can trigger inflammatory cascades (cytokine/chemokine production, upregulation of MMPs, leukocyte infiltration), cytotoxic events via oxidative stress and BEC apoptosis that further enhance BBB dysfunction [184, 185]. The mechanisms of $\mathrm{BBB}$ dysfunction in intracerebral and subarachnoid hemorrhage have, however, been much less studied than ischemic stroke and may differ between the two types of hemorrhage.

As with ischemia, insights into the mechanisms of $\mathrm{BBB}$ injury in hemorrhagic stroke can be gained from in vitro models. For example, the effects of different hematoma components can be examined; e.g. thrombin, hemoglobin and iron [186, 187]. There are similarities in the model/conditions to the ischemic stroke in vitro model [188]. Similar to ischemic studies, the direct effects of certain inflammatory conditions (i.e. treatment with IL-6) to resemble hemorrhagic stroke can be studied (Table 1) [189]. Replicating the mass effect in vitro is more difficult. While any ischemia can be mimicked by OGD, the physical effects of the hematoma (e.g. shearing or stretching) has not been examined. It is possible that some of the stretch models developed to study traumatic brain injury may be of use.

Compared to ischemic stroke studies, studies examining the effects of hemorrhagic stroke on the BBB/ NVU in vitro are in their "infancy". They have generally focused on a single facet of that injury (e.g. the effects of a single blood component). Some of the more recent in vitro models may enable a better replication of in vivo 
hemorrhage, e.g. having blood in the extravascular chamber with or without reductions in flow.

\section{Vascular malformation and BBB models system}

In vascular malformations, $\mathrm{BBB}$ damage could be an underlying cause of the pathology (CCMs) or the $\mathrm{BBB}$ may be a site of secondary damage (AVMs and HHT). In AVMs and HHT, lesions form due to a redirection of blood flow from arteries/arterioles to veins/venules, bypassing downstream capillary beds and reducing the proper brain oxygenation [8]. One predominant complication is blood vessel rupture and brain hemorrhage. Several genetic factors (polymorphism of EPHB4, IL-6, $T N F \alpha, I L-1 \beta, A P O E$, genes) are indicated as risk factors for hemorrhage of AVM lesions [8]. AVM is also a component of several hereditary disorders, like hereditary hemorrhagic telangiectasia (HHT, also known as OslerWeber-Rendu disease), Wyburn-Mason syndrome, and Sturge-Weber syndrome characterized by mutations of endoglin (ENG) or Alk1 (ACVRL1) [7, 8]. Some pathogenic processes in AVM lesions are abnormal angiogenesis, blood flow alterations and cellular remodeling of the $\mathrm{BBB} / \mathrm{NVU}$. A defect in pericyte function has been suggested to be a key factor for AVM lesion initiation and progression, although the direct involvement is still unknown [190]. The BBB dysfunction found in AVMs is mostly associated with secondary effects of on-going inflammation in perivascular space and delayed hypoxic injury due to hemorrhage [183]. There are few in vitro studies that address BBB injury in AVMs. The commonly used models examine the effects of $I L-6, T N F \alpha, I L-1 \beta$ on the $\mathrm{BBB}$ permeability, pericytes/BEC interaction and hypoxic conditions-cells exposed to conditions of reduced oxygen $\left(1-2 \% \mathrm{O}_{2}\right)$ with normal glucose supply $[189,190]$.

Another form of cerebrovascular malformation are the CCMs. These occur as spontaneous and hereditary forms, with the latter due to mutations in one of three genes, CCM1, CCM2 and CCM3 [10]. CCMs lesions initiate in the capillary beds with anterograde and retrograde progression. Histologically, CCMs lesions are enlarged thin-walled vascular structures without intervening brain parenchyma, lined with ECs with poorly formed tight TJs, with gaps often noted between individual cells. There is a loss of pericytes, astrocytic foot processes and normal nervous tissues [31]. Focal BBB breakdown takes center stage in CCMs lesion development. Some of the underlying mechanisms involved include abnormal angiogenesis, disorganization of the endothelial TJ complex, alterations in the signaling pathways that regulate these processes, alteration in anticoagulation vascular domain and inflammation [191].
Current CCM in vitro models are largely based on monocultures of BEC with transfection to knockdown one of the CCM genes $[59,95]$. However, these models suffer many limitations like low yield of cell transfection due to transfection resistant $\mathrm{BEC}$, inappropriate species (using murine cells) or cell source (e.g. using HUVEC) that may significantly alter the outcome of studies.

A future direction for modeling of vascular malformations and particularly CCMs is in developing and utilizing iPSC and BBB-on-a-chip from the patients with CCMs, providing a unique model system for developing high throughput screening as well as understanding the mechanisms of vascular malformation. In addition, while most attention has focused on the inherited forms of CCM, in vitro models can also give insight into how a sporadic mutation in CCM-related genes can alter the phenotype of nearby cells to cause a lesion [192]. In vitro models are well-suited for examining such cell: cell signaling and devising new therapies for preventing such phenotypic transformation.

\section{Vascular dementia and the BBB}

$\mathrm{BBB}$ dysfunction is considered a contributing factor in vascular dementia. Cerebrovascular alterations include reduced microvascular density (particularly in hippocampus, white matter and cortex), and loss of angiogenic capacity and microvascular plasticity [13-15]. Frequently, micro artheroma or lipid emboli are found in cerebral microvessels and most vessels have focal subclinical inflammatory reactions, increased permeability and perivascular edema [13]. Based on pathological and clinical MRI aging studies, as well as age-related diseases, $\mathrm{BBB}$ hyperpermeability together with hypoperfusion is one of the critical signs of cerebrovascular aging and it is manifested as small persistent leakage in specific brain areas, such as subcortical white matter and hippocampus $[13,14]$. Leakage is associated with abnormal perivascular and parenchymal accumulation of albumin, fibrinogen and IgG [193]. This is associated with a loss of immunostaining for the $\mathrm{TJ}$ proteins (occludin, claudin- 5 and ZO-1), as well as decreased pericyte numbers and swollen astrocytic end-feet. In addition, aging BECs "suffer" metabolic damage manifested as reduced expression of glucose transporter 1, increased pinocytotic vesicles and decreased mitochondria [13, 193]. Similarly, the inherited form of cerebral small vessel diseases, CADASIL and CARASIL, have white matter lesions, frequent lacunar infarcts and enlarged perivascular spaces with persistent leakage of BBB $[19,20]$. The BBB hyperpermeability is associated with pericyte dysfunction that destabilizes the barrier and consequently causes development of an inflammatory response and enhances BBB injury [19]. 
Among the underlying mechanisms of focal BBB/NVU dysfunction in aging and vascular dementia, are oxidative stress (excessive reactive oxygen species generation), overproduction of cytokines and proteases (i.e. MMP2, MMP9, IL1 $\beta$, TNF- $\alpha$ ) and excessive DNA damage response [14]. All cell types are impacted by the "aging" process, including astrocytes, pericytes, microglia cells and particularly BECs. The latter are highly susceptible to oxidative stress, with reduced proliferation and sensitivity to pro-angiogenic factors, excessive cell death (apoptosis and autophagy), compromised ability to prevent blood coagulation events and respond to vasodilatory factors, and support for chronic inflammatory processes [13].

Currently, how can this condition be modeled in vitro? The most reliable models involve isolation of $\mathrm{BBB} / \mathrm{NVU}$ cells from aging brain tissue and generating the in vitro models to mimic the aging NVU microenvironment. However, those model systems have several limitations in relation to the cell viability and their proliferative capacity that restrict establishing the in vitro $\mathrm{BBB} / \mathrm{NVU}$ models. Another approach is inducing senescence-specific properties in BBB/NVU cells. These models are based on targeting one of several mechanisms involved in cell senescence: oxidative stress, DNA damage and inflammation. Oxidative stress causes cell senescence in vitro via depletion of intracellular $\mathrm{NAD}^{+}$due to excessive activation of poly(ADP-ribose)polymerase important for DNA repair. For example, if $\mathrm{H}_{2} \mathrm{O}_{2}(50 \mu \mathrm{M})$ is added to culture media for $6 \mathrm{~h}$ for BEC monolayers or 2-D cocultures it induces phenotypic changes characteristic of the aging BBB [194-196]. However, several studies have indicated that the efficacy of $\mathrm{H}_{2} \mathrm{O}_{2}$ depends on cell type, number of cell passages (particularly with ECs), cell cycle and cell sensitivity to this genotoxic agent. Another method to induce senescence is DNA damage that is a prerequisite for senescence phenotype and genomic lesions. A marker for DNA damage is accumulation of phosphorylated form of histone $\mathrm{H} 2 \mathrm{AX}(\gamma-\mathrm{H} 2 \mathrm{AX})$ which marks sites of DNA double strand breaks and is required for maintaining genome integrity [197]. DNA damage can be induced by gamma-irradiation and shortening of telomeres or can occur spontaneously by repetitive passage of cells (replicative senescence) [195, 198, 199]. Modification of cell metabolism, particularly enhancing the rate of glycolysis, can also induce cell senescence [200]. There are two possible methods to induce senescence in cells by targeting glycolysis, one is based on exposure to high glucose levels that potentiates mitochondrial dysfunction, increases reactive oxygen species and the other on targeting (attenuating) the growth hormone/IGF signaling pathway and propagating senescence signals to neighboring cells [201, 202]. Inflammation is often used for modeling the aging phenotype and injury of BBB/NVU. Exposure of the in vitro $\mathrm{BBB}$ or single cell cultures to non-toxic concentrations of IL- $1 \beta$ and TNF- $\alpha$ for $24 \mathrm{~h}$ can produce a senescence phenotype in cells/components of the BBB [203]. Another protocol for inducing chronic inflammation for cell senescence includes genetic manipulation of signaling molecules upstream of pro-inflammatory cytokine secretion (i.e. nuclear factor-kappa B (NFkB), CCL2, CXCL8) [204]. Overexpression of progerin (a mutation that causes premature aging in humans) or treatment with pharmacological inhibitors of telomerase are recommended for models that use iPSC [205]. In sum, all of these models can induce a senescence phenotype in components of the BBB/NVU and they could represent tools for modeling BBB aging in vitro. They can be used to assess important characteristics, BBB integrity (permeability), barrier metabolic state, cell-cell interaction and inflammatory remodeling. Characteristics of the models/conditions are provided in Table 1.

Studying human vascular dementia in vitro poses unique challenges. While progress is being made delineating the effects of aging on the cerebrovasculature, vascular dementia involves a long-term interaction of multiple factors, including flow and metabolic changes, in the aging brain. One possible future direction is to study the BBB/NVU of patients where cerebral small vessel disease has a genetic cause.

Regarding CADASIL and CARASIL, the underlying mechanisms of BBB leakage are still largely unknown. Due to identified mutations in two genes, NOTCH 3 (CADASIL) and HTRA1 (CARASIL), the likely best approach is patient-specific disease modeling and generation of human iPSC vascular cells that will resemble the phenotype of the diseases and organization of the $\mathrm{BBB} / \mathrm{NVU}$. The first step was made recently by generating NOTCH3 iPSCs [206].

\section{Conclusion and future directions}

With all the limitations and caveats of in vitro modeling of the $\mathrm{BBB} / \mathrm{NVU}$, current models have dissected some of the critical processes involved in $\mathrm{BBB} / \mathrm{NVU}$ injury and remodeling in cerebrovascular disease. Further improvements in BBB model fabrication as well improving the in vitro environmental conditions are important steps in recapitulating the pathology of cerebrovascular disease at the BBB. However, equally important is the "humanizing" of models and generating human iPSCs that best mimic the BBB phenotype. A step forward will be "personalized" models of particular cerebrovascular diseases where a particular donor's iPSCs are used to generate different NVU cell types. Progress towards this goal is being made in new generations of BBB-on-a-chip models. Developing new and improved BBB-on-a-chip will 
facilitate discoveries of underlying mechanisms involved in BBB dysfunction in different cerebrovascular diseases. It will limit caveats related to species differences and open a path for more translational research (personalized medicine and drug testing) in vitro.

\section{Acknowledgements}

This work was supported by Public Health Service grant and RFA057928 from National Institute of Aging (A.V.A), NS111205 form National Institute of Neurological Disorders and Stroke (A.V.A).

\section{Authors' contributions}

All authors, SMS, CP, GMR RFK and AVA, contributed to the writing, illustration and reviewing of the manuscript. All authors read and approved the final manuscript.

\section{Availability of data and materials}

Not applicable.

\section{Ethics approval and consent to participate}

Not applicable.

\section{Competing interests}

The authors declare that the research was conducted in the absence of any commercial or financial relationships that could be construed as a potential conflict of interest. RFK is a co-editor in chief of Fluids Barriers CNS.

\section{Author details}

${ }^{1}$ Department of Pathology, University of Michigan Medical School, 7520 MSRB I, 1150 West Medical Center Dr, Ann Arbor, MI 48109-5602, USA. ${ }^{2}$ Department of Neurosurgery, University of Michigan Medical School, Ann Arbor, MI, USA.

${ }^{3}$ Department of Molecular Integrative Physiology, University of Michigan Medical School, Ann Arbor, MI, USA. ${ }^{4}$ Graduate Program in Neuroscience, University of Michigan Medical School, Ann Arbor, MI, USA.

Received: 31 March 2020 Accepted: 15 June 2020

Published online: 16 July 2020

\section{References}

1. Benjamin EJ, Muntner P, Alonso A, Bittencourt MS, Callaway CW, Carson $A P$, et al. Heart disease and stroke statistics-2019 update: a report from the American Heart Association. Circulation. 2019;139(10):e56-528.

2. Topcuoglu MA, Liu L, Kim DE, Gurol ME. Updates on prevention of cardioembolic strokes. J Stroke. 2018;20(2):180-96.

3. Tsai HH, Kim JS, Jouvent E, Gurol ME. Updates on prevention of hemorrhagic and lacunar strokes. J Stroke. 2018;20(2):167-79.

4. Reed GL, Houng AK, Wang D. Microvascular thrombosis, fibrinolysis, ischemic injury, and death after cerebral thromboembolism are affected by levels of circulating alpha2-antiplasmin. Arterioscler Thromb Vasc Biol. 2014;34(12):2586-93.

5. Kalaria RN, Akinyemi R, Ihara M. Stroke injury, cognitive impairment and vascular dementia. Biochim Biophys Acta. 2016;1862(5):915-25.

6. Mok VCT, Lam BYK, Wang Z, Liu W, Au L, Leung EYL, et al. Delayed-onset dementia after stroke or transient ischemic attack. Alzheimers Dement. 2016;12(11):1167-76.

7. Panagos PD, Jauch EC, Broderick JP. Intracerebral hemorrhage. Emerg Med Clin North Am. 2002;20(3):631-55.

8. Sorenson TJ, Brinjikji W, Bortolotti C, Kaufmann G, Lanzino G. Recurrent brain arteriovenous malformations (avms): a systematic review. World Neurosurg. 2018;116:e856-66.

9. Willemse RB, Mager JJ, Westermann CJ, Overtoom TT, Mauser $H_{\text {, }}$ Wolbers JG. Bleeding risk of cerebrovascular malformations in hereditary hemorrhagic telangiectasia. J Neurosurg. 2000;92(5):779-84.

10. Awad IA, Polster SP. Cavernous angiomas: deconstructing a neurosurgical disease. J Neurosurg. 2019;131(1):1-13.
11. Vallon M, Chang J, Zhang H, Kuo CJ. Developmental and pathological angiogenesis in the central nervous system. Cell Mol Life Sci. 2014;71(18):3489-506.

12. Wolters FJ, Ikram MA. Epidemiology of Vascular Dementia. Arterioscler Thromb Vasc Biol. 2019;39(8):1542-9.

13. Ostergaard L, Engedal TS, Moreton F, Hansen MB, Wardlaw JM, Dalkara T, et al. Cerebral small vessel disease: capillary pathways to stroke and cognitive decline. J Cereb Blood Flow Metab. 2016;36(2):302-25.

14. Srinivasan V, Braidy N, Chan EK, Xu YH, Chan DK. Genetic and environmental factors in vascular dementia: an update of blood brain barrier dysfunction. Clin Exp Pharmacol Physiol. 2016;43(5):515-21.

15. van de Vorst IE, Koek HL, de Vries R, Bots ML, Reitsma JB, Vaartjes I. Effect of vascular risk factors and diseases on mortality in individuals with dementia: a systematic review and meta-analysis. J Am Geriatr Soc. 2016;64(1):37-46.

16. Loeb C. Binswanger's disease is not a single entity. Neurol Sci. 2000;21(6):343-8.

17. Sondergaard CB, Nielsen JE, Hansen CK, Christensen H. Hereditary cerebral small vessel disease and stroke. Clin Neurol Neurosurg. 2017:155:45-57.

18. Pippucci T, Maresca A, Magini P, Cenacchi G, Donadio V, Palombo F, et al Homozygous NOTCH3 null mutation and impaired NOTCH3 signaling in recessive early-onset arteriopathy and cavitating leukoencephalopathy. EMBO Mol Med. 2015;7(6):848-58.

19. Zellner A, Scharrer E, Arzberger T, Oka C, Domenga-Denier V, Joutel A, et al. CADASIL brain vessels show a HTRA1 loss-of-function profile. Acta Neuropathol. 2018:136(1):111-25.

20. Ibrahimi M, Nozaki H, Lee A, Onodera O, Reichwein R, Wicklund M, et al. A CARASIL patient from americas with novel mutation and atypical features: case presentation and literature review. Cerebrovasc Dis. 2017:44(3-4):135-40.

21. Duvernoy HM, Delon S, Vannson JL. Cortical blood vessels of the human brain. Brain Res Bull. 1981;7(5):519-79.

22. Cipolla MJ. The cerebral circulation. Integrated systems physiology: from molecule to function. San Rafael; 2009.

23. Hirsch S, Reichold J, Schneider M, Szekely G, Weber B. Topology and hemodynamics of the cortical cerebrovascular system. J Cereb Blood Flow Metab. 2012;32(6):952-67.

24. Allt G, Lawrenson JG. Pericytes: cell biology and pathology. Cells Tissues Organs. 2001;169(1):1-11.

25. Wei L, Otsuka T, Acuff V, Bereczki D, Pettigrew K, Patlak C, et al. The velocities of red cell and plasma flows through parenchymal microvessels of rat brain are decreased by pentobarbital. J Cereb Blood Flow Metab. 1993;13(3):487-97.

26. Weber B, Keller AL, Reichold J, Logothetis NK. The microvascular system of the striate and extrastriate visual cortex of the macaque. Cereb Cortex. 2008;18(10):2318-30.

27. Vanlandewijck M, He L, Mae MA, Andrae J, Ando K, Del Gaudio F, et al. A molecular atlas of cell types and zonation in the brain vasculature. Nature. 2018;554(7693):475-80.

28. Mae M, Armulik A, Betsholtz C. Getting to know the cast - cellular interactions and signaling at the neurovascular unit. Curr Pharm Des. 2011;17(26):2750-4

29. Muoio V, Persson PB, Sendeski MM. The neurovascular unit-concept review. Acta Physiol (Oxf). 2014;210(4):790-8.

30. Coomber BL, Stewart PA. Three-dimensional reconstruction of vesicles in endothelium of blood-brain barrier versus highly permeable microvessels. Anat Rec. 1986;215(3):256-61.

31. Nakada T, Kwee IL, Igarashi H, Suzuki Y. Aquaporin-4 functionality and virchow-robin space water dynamics: physiological model for neurovascular coupling and glymphatic flow. Int J Mol Sci. 2017;18(8):1798.

32. Hall CN, Reynell C, Gesslein B, Hamilton NB, Mishra A, Sutherland BA, et al. Capillary pericytes regulate cerebral blood flow in health and disease. Nature. 2014;508(7494):55-60.

33. Wolburg H. Orthogonal arrays of intramembranous particles: a review with special reference to astrocytes. J Hirnforsch. 1995:36(2):239-58.

34. Wolburg-Buchholz K, Mack AF, Steiner E, Pfeiffer F, Engelhardt B, Wolburg H. Loss of astrocyte polarity marks blood-brain barrier impairment during experimental autoimmune encephalomyelitis. Acta Neuropathol. 2009;118(2):219-33. 
35. Iorio R, Fryer JP, Hinson SR, Fallier-Becker P, Wolburg H, Pittock SJ, et al. Astrocytic autoantibody of neuromyelitis optica (NMO-lgG) binds to aquaporin-4 extracellular loops, monomers, tetramers and high order arrays. J Autoimmun. 2013;40:21-7.

36. Chen Y, Wang L, Zhang L, Chen B, Yang L, Li X, et al. Inhibition of connexin 43 hemichannels alleviates cerebral ischemia/reperfusion injury via the TLR4 signaling pathway. Front Cell Neurosci. 2018;12:372.

37. Zhou D, Huang X, Xie Y, Deng Z, Guo J, Huang H. Astrocytes-derived VEGF exacerbates the microvascular damage of late delayed RBI. Neuroscience. 2019;408:14-21.

38. Goldmann T, Wieghofer P, Jordao MJ, Prutek F, Hagemeyer N, Frenzel $\mathrm{K}$, et al. Origin, fate and dynamics of macrophages at central nervous system interfaces. Nat Immunol. 2016;17(7):797-805.

39. Li Q, Cheng Z, Zhou L, Darmanis S, Neff NF, Okamoto J, et al. Developmental heterogeneity of microglia and brain myeloid cells revealed by deep single-cell RNA sequencing. Neuron. 2019;101(2):207-23.

40. Haruwaka K, Ikegami A, Tachibana Y, Ohno N, Konishi H, Hashimoto A, et al. Dual microglia effects on blood brain barrier permeability induced by systemic inflammation. Nat Commun. 2019;10(1):5816.

41. Joost E, Jordao MJC, Mages B, Prinz M, Bechmann I, Krueger M. Microglia contribute to the glia limitans around arteries, capillaries and veins under physiological conditions, in a model of neuroinflammation and in human brain tissue. Brain Struct Funct. 2019;224(3):1301-14.

42. Sun $Y$, Chen $X$, Zhang $X$, Shen $X$, Wang M, Wang X, et al. Beta2-adrenergic receptor-mediated HIF-1alpha upregulation mediates bloodbrain barrier damage in acute cerebral ischemia. Front Mol Neurosci. 2017;10:257.

43. An J, Haile WB, Wu F, Torre E, Yepes M. Tissue-type plasminogen activator mediates neuroglial coupling in the central nervous system. Neuroscience. 2014;257:41-8.

44. Liebner S, Plate KH. Differentiation of the brain vasculature: the answer came blowing by the Wnt. J Angiogenes Res. 2010;2:1.

45. Singh VB, Singh MV, Piekna-Przybylska D, Gorantla S, Poluektova LY, Maggirwar SB. Sonic Hedgehog mimetic prevents leukocyte infiltration into the CNS during acute HIV infection. Sci Rep. 2017;7(1):9578.

46. Joo F. Endothelial cells of the brain and other organ systems: some similarities and differences. Prog Neurobiol. 1996;48(3):255-73.

47. Stamatovic SM, Johnson AM, Keep RF, Andjelkovic AV. Junctional proteins of the blood-brain barrier: new insights into function and dysfunction. Tissue Barriers. 2016;4(1):e1154641.

48. Mitic LL, Anderson JM. Molecular architecture of tight junctions. Annu Rev Physiol. 1998;60:121-42

49. Staddon JM, Rubin LL. Cell adhesion, cell junctions and the blood-brain barrier. Curr Opin Neurobiol. 1996;6(5):622-7.

50. Nitta T, Hata M, Gotoh S, Seo Y, Sasaki H, Hashimoto N, et al. Size-selective loosening of the blood-brain barrier in claudin-5-deficient mice. J Cell Biol. 2003;161(3):653-60.

51. Ohtsuki S, Sato S, Yamaguchi H, Kamoi M, Asashima T, Terasaki T. Exogenous expression of claudin-5 induces barrier properties in cultured rat brain capillary endothelial cells. J Cell Physiol. 2007;210(1):81-6.

52. Gonzalez-Mariscal L, Betanzos A, Avila-Flores A. MAGUK proteins: structure and role in the tight junction. Semin Cell Dev Biol. 2000;11(4):315-24.

53. Gonzalez-Mariscal L, Betanzos A, Nava P, Jaramillo BE. Tight junction proteins. Prog Biophys Mol Biol. 2003;81(1):1-44.

54. Hicks K, O'Neil RG, Dubinsky WS, Brown RC. TRPC-mediated actin-myosin contraction is critical for BBB disruption following hypoxic stress. Am J Physiol Cell Physiol. 2010;298(6):C1583-93.

55. Lai CH, Kuo KH, Leo JM. Critical role of actin in modulating BBB permeability. Brain Res Brain Res Rev. 2005;50(1):7-13.

56. Hatte G, Prigent C, Tassan JP. Tight junction-associated protein GEF-H1 in the neighbours of dividing epithelial cells is essential for adaptation of cell-cell membrane during cytokinesis. Exp Cell Res. 2018;371(1):72-82.

57. Hubner K, Cabochette P, Dieguez-Hurtado R, Wiesner C, Wakayama Y, Grassme KS, et al. Wnt/beta-catenin signaling regulates VE-cadherinmediated anastomosis of brain capillaries by counteracting S1 pr 1 signaling. Nat Commun. 2018;9(1):4860.

58. Liebner S, Corada M, Bangsow T, Babbage J, Taddei A, Czupalla CJ, et al. Wnt/beta-catenin signaling controls development of the blood-brain barrier. J Cell Biol. 2008;183(3):409-17.
59. Johnson AM, Roach JP, Hu A, Stamatovic SM, Zochowski MR, Keep RF, et al. Connexin 43 gap junctions contribute to brain endothelial barrier hyperpermeability in familial cerebral cavernous malformations type III by modulating tight junction structure. FASEB J. 2018;32(5):2615-29.

60. De Bock M, Leybaert L, Giaume C. Connexin channels at the glio-vascular interface: gatekeepers of the brain. Neurochem Res. 2017;42(9):2519-36.

61. Bhowmick S, D'Mello V, Caruso D, Wallerstein A, Abdul-Muneer PM. Impairment of pericyte-endothelium crosstalk leads to blood-brain barrier dysfunction following traumatic brain injury. Exp Neurol. 2019;317:260-70.

62. Barar J, Rafi MA, Pourseif MM, Omidi Y. Blood-brain barrier transport machineries and targeted therapy of brain diseases. Bioimpacts. 2016;6(4):225-48

63. Ruano-Salguero JS, Lee KH. Antibody transcytosis across brain endothelial-like cells occurs nonspecifically and independent of FcRn. Sci Rep. 2020;10(1):3685.

64. Ge S, Song L, Serwanski DR, Kuziel WA, Pachter JS. Transcellular transport of CCL2 across brain microvascular endothelial cells. J Neurochem. 2008;104(5):1219-32.

65. Stamatovic SM, Sladojevic N, Keep RF, Andjelkovic AV. Relocalization of junctional adhesion molecule A during inflammatory stimulation of brain endothelial cells. Mol Cell Biol. 2012;32(17):3414-27.

66. Braissant O, Gotoh T, Loup M, Mori M, Bachmann C. Differential expression of the cationic amino acid transporter 2(B) in the adult rat brain. Brain Res Mol Brain Res. 2001;91(1-2):189-95.

67. Ohtsuki S, Asaba H, Takanaga H, Deguchi T, Hosoya K, Otagiri M, et al. Role of blood-brain barrier organic anion transporter 3 (OAT3) in the efflux of indoxyl sulfate, a uremic toxin: its involvement in neurotransmitter metabolite clearance from the brain. J Neurochem. 2002;83(1):57-66.

68. Tachikawa M, Kasai Y, Yokoyama R, Fujinawa J, Ganapathy V, Terasaki $T$, et al. The blood-brain barrier transport and cerebral distribution of guanidinoacetate in rats: involvement of creatine and taurine transporters. J Neurochem. 2009;111(2):499-509.

69. Cansev M. Uridine and cytidine in the brain: their transport and utilization. Brain Res Rev. 2006;52(2):389-97.

70. Gao B, Hagenbuch B, Kullak-Ublick GA, Benke D, Aguzzi A, Meier PJ. Organic anion-transporting polypeptides mediate transport of opioid peptides across blood-brain barrier. J Pharmacol Exp Ther. 2000;294(1):73-9.

71. Taogoshi T, Nomura A, Murakami T, Nagai J, Takano M. Transport of prostaglandin E1 across the blood-brain barrier in rats. J Pharm Pharmacol. 2005;57(1):61-6.

72. Gao B, Stieger B, Noe B, Fritschy JM, Meier PJ. Localization of the organic anion transporting polypeptide 2 (Oatp2) in capillary endothelium and choroid plexus epithelium of rat brain. J Histochem Cytochem. 1999:47(10):1255-64.

73. Guo Y, Jiang L. Organic anion transporting polypeptide 2 transports valproic acid in rat brain microvascular endothelial cells. Neurol Res. 2016;38(7):634-9.

74. Wakayama K, Ohtsuki S, Takanaga H, Hosoya K, Terasaki T. Localization of norepinephrine and serotonin transporter in mouse brain capillary endothelial cells. Neurosci Res. 2002;44(2):173-80.

75. Andre P, Saubamea B, Cochois-Guegan V, Marie-Claire C, Cattelotte J, Smirnova $M$, et al. Transport of biogenic amine neurotransmitters at the mouse blood-retina and blood-brain barriers by uptake1 and uptake2. J Cereb Blood Flow Metab. 2012;32(11):1989-2001.

76. Takanaga H, Ohtsuki S, Hosoya K, Terasaki T. GAT2/BGT-1 as a system responsible for the transport of gamma-aminobutyric acid at the mouse blood-brain barrier. J Cereb Blood Flow Metab. 2001:21(10):1232-9.

77. Tetsuka K, Takanaga H, Ohtsuki S, Hosoya K, Terasaki T. The I-isomerselective transport of aspartic acid is mediated by ASCT2 at the bloodbrain barrier. J Neurochem. 2003;87(4):891-901.

78. Faassen F, Vogel G, Spanings H, Vromans H. Caco-2 permeability, P-glycoprotein transport ratios and brain penetration of heterocyclic drugs. Int J Pharm. 2003;263(1-2):113-22.

79. Bauer M, Zeitlinger M, Karch R, Matzneller P, Stanek J, Jager W, et al. Pgpmediated interaction between $(\mathrm{R})-[11 \mathrm{C}]$ verapamil and tariquidar at the 
human blood-brain barrier: a comparison with rat data. Clin Pharmacol Ther. 2012;91(2):227-33.

80. Brzozowska N, Li KM, Wang XS, Booth J, Stuart J, McGregor IS, et al. ABC transporters P-gp and Bcrp do not limit the brain uptake of the novel antipsychotic and anticonvulsant drug cannabidiol in mice. PeerJ. 2016;4:e2081.

81. Lingineni K, Belekar V, Tangadpalliwar SR, Garg P. The role of multidrug resistance protein (MRP-1) as an active efflux transporter on bloodbrain barrier (BBB) permeability. Mol Divers. 2017;21(2):355-65.

82. Helms HC, Hersom M, Kuhlmann LB, Badolo L, Nielsen CU, Brodin B. An electrically tight in vitro blood-brain barrier model displays net brainto-blood efflux of substrates for the ABC transporters, P-gp, Bcrp and Mrp-1. AAPS J. 2014;16(5):1046-55.

83. Keep RF, Xiang J, Betz AL. Potassium transport at the blood-brain and blood-CSF barriers. Adv Exp Med Biol. 1993;331:43-54.

84. O'Donnell ME. Blood-brain barrier Na transporters in ischemic stroke. Adv Pharmacol. 2014;71:113-46.

85. Yamada K. Vascular potassium channels in NVC. Prog Brain Res. 2016;225:63-73.

86. Janigro D, West GA, Gordon EL, Winn HR. ATP-sensitive K+ channels in rat aorta and brain microvascular endothelial cells. Am J Physiol. 1993:265(3 Pt 1):C812-21.

87. Berrout J, Jin M, O'Neil RG. Critical role of TRPP2 and TRPC1 channels in stretch-induced injury of blood-brain barrier endothelial cells. Brain Res. 2012;1436:1-12.

88. Simard JM, Tsymbalyuk O, Ivanov A, Ivanova S, Bhatta S, Geng Z, et al. Endothelial sulfonylurea receptor 1-regulated NC Ca-ATP channels mediate progressive hemorrhagic necrosis following spinal cord injury. J Clin Invest. 2007;117(8):2105-13.

89. Yakubu MA, Leffler CW. L-type voltage-dependent $\mathrm{Ca}^{2+}$ channels in cerebral microvascular endothelial cells and ET-1 biosynthesis. Am J Physiol Cell Physiol. 2002;283(6):C1687-95.

90. Breschi A, Gingeras TR, Guigo R. Comparative transcriptomics in human and mouse. Nat Rev Genet. 2017;18(7):425-40.

91. Nguyen TV, Frye JB, Zbesko JC, Stepanovic K, Hayes M, Urzua A, et al. Multiplex immunoassay characterization and species comparison of inflammation in acute and non-acute ischemic infarcts in human and mouse brain tissue. Acta Neuropathol Commun. 2016;4(1):100.

92. Wang MM, Zhang X, Lee SJ, Maripudi S, Keep RF, Johnson AM, et al. Expression of periaxin (PRX) specifically in the human cerebrovascular system: PDZ domain-mediated strengthening of endothelial barrier function. Sci Rep. 2018;8(1):10042

93. Warren MS, Zerangue N, Woodford K, Roberts LM, Tate EH, Feng B, et al. Comparative gene expression profiles of $A B C$ transporters in brain microvessel endothelial cells and brain in five species including human. Pharmacol Res. 2009;59(6):404-13.

94. Abbott NJ, Dolman DE, Drndarski S, Fredriksson SM. An improved in vitro blood-brain barrier model: rat brain endothelial cells cocultured with astrocytes. Methods Mol Biol. 2012;814:415-30.

95. Stamatovic SM, Sladojevic N, Keep RF, Andjelkovic AV. PDCD10 (CCM3) regulates brain endothelial barrier integrity in cerebral cavernous malformation type 3: role of CCM3-ERK1/2-cortactin cross-talk. Acta Neuropathol. 2015;130(5):731-50.

96. Dimitrijevic OB, Stamatovic SM, Keep RF, Andjelkovic AV. Effects of the chemokine CCL2 on blood-brain barrier permeability during ischemiareperfusion injury. J Cereb Blood Flow Metab. 2006;26(6):797-810.

97. Helms HC, Abbott NJ, Burek M, Cecchelli R, Couraud PO, Deli MA, et al. In vitro models of the blood-brain barrier: an overview of commonly used brain endothelial cell culture models and guidelines for their use. J Cereb Blood Flow Metab. 2016;36(5):862-90.

98. Sabbagh MF, Nathans J. A genome-wide view of the de-differentiation of central nervous system endothelial cells in culture. Elife. 2020;9.

99. Sano Y, Shimizu F, Abe M, Maeda T, Kashiwamura Y, Ohtsuki S, et al. Establishment of a new conditionally immortalized human brain microvascular endothelial cell line retaining an in vivo blood-brain barrier function. J Cell Physiol. 2010;225(2):519-28.

100. Ades EW, Candal FJ, Swerlick RA, George VG, Summers S, Bosse DC, et al. HMEC-1: establishment of an immortalized human microvascular endothelial cell line. J Invest Dermatol. 1992;99(6):683-90.
101. Weksler BB, Subileau EA, Perriere N, Charneau P, Holloway K, Leveque $M$, et al. Blood-brain barrier-specific properties of a human adult brain endothelial cell line. FASEB J. 2005;19(13):1872-4.

102. Price TN, Burke JF, Mayne LV. A novel human astrocyte cell line (A735) with astrocyte-specific neurotransmitter function. Vitro Cell Dev Biol Anim. 1999;35(5):279-88.

103. Parker KK, Norenberg MD, Vernadakis A. "Transdifferentiation" of C6 glial cells in culture. Science. 1980;208(4440):179-81.

104. Nagai A, Nakagawa E, Hatori K, Choi HB, McLarnon JG, Lee MA, et al. Generation and characterization of immortalized human microglial cell lines: expression of cytokines and chemokines. Neurobiol Dis. 2001;8(6):1057-68.

105. Umehara K, Sun Y, Hiura S, Hamada K, Itoh M, Kitamura K, et al. A new conditionally immortalized human fetal brain pericyte cell line: establishment and functional characterization as a promising tool for human brain pericyte studies. Mol Neurobiol. 2018;55(7):5993-6006.

106. Taylor MA, Kan HL, Gollapudi BB, Marty MS. An in vitro developmental neurotoxicity screening assay for retinoic acid-induced neuronal differentiation using the human NT2/D1 cell line. Neurotoxicology. 2019;73:258-64.

107. Akerman KE, Scott IG, Andersson LC. Functional differentiation of a human ganglion cell derived neuroblastoma cell line SH-SY5Y induced by a phorbol ester (TPA). Neurochem Int. 1984;6(1):77-80.

108. Veszelka S, Toth A, Walter FR, Toth AE, Grof I, Meszaros M, et al. Comparison of a rat primary cell-based blood-brain barrier model with epithelial and brain endothelial cell lines: gene expression and drug transport. Front Mol Neurosci. 2018;11:166

109. Park IH, Zhao R, West JA, Yabuuchi A, Huo H, Ince TA, et al. Reprogramming of human somatic cells to pluripotency with defined factors. Nature. 2008:451(7175):141-6.

110. Bao X, Adil MM, Muckom R, Zimmermann JA, Tran A, Suhy N, et al. Gene Editing to generate versatile human pluripotent stem cell reporter lines for analysis of differentiation and lineage tracing. Stem Cells. 2019;37(12):1556-66.

111. Belle K, Shabazz FS, Nuytemans K, Davis DA, Ali A, Young JL, et al. Generation of disease-specific autopsy-confirmed iPSCs lines from postmortem isolated peripheral blood mononuclear cells. Neurosci Lett. 2017;637:201-6.

112. Biegel D, Spencer DD, Pachter JS. Isolation and culture of human brain microvessel endothelial cells for the study of blood-brain barrier properties in vitro. Brain Res. 1995;692(1-2):183-9.

113. Dos Santos Rodrigues B, Oue H, Banerjee A, Kanekiyo T, Singh J. Dual functionalized liposome-mediated gene delivery across triple co-culture blood brain barrier model and specific in vivo neuronal transfection. J Control Release. 2018;286:264-78.

114. Hayashi K, Nakao S, Nakaoke R, Nakagawa S, Kitagawa N, Niwa M. Effects of hypoxia on endothelial/pericytic co-culture model of the blood-brain barrier. Regul Pept. 2004;123(1-3):77-83.

115. Colgan OC, Collins NT, Ferguson G, Murphy RP, Birney YA, Cahill PA, et al. Influence of basolateral condition on the regulation of brain microvascular endothelial tight junction properties and barrier function. Brain Res. 2008;1193:84-92.

116. Wu KW, Kou ZW, Mo JL, Deng XX, Sun FY. Neurovascular coupling protects neurons against hypoxic injury via inhibition of potassium currents by generation of nitric oxide in direct neuron and endothelium cocultures. Neuroscience. 2016;334:275-82.

117. Matsumoto J, Dohgu S, Takata F, Nishioku T, Sumi N, Machida T, et al. Lipopolysaccharide-activated microglia lower P-glycoprotein function in brain microvascular endothelial cells. Neurosci Lett. 2012;524(1):45-8.

118. Dehouck MP, Meresse S, Delorme P, Fruchart JC, Cecchelli R. An easier, reproducible, and mass-production method to study the blood-brain barrier in vitro. J Neurochem. 1990;54(5):1798-801.

119. Stone NL, England TJ, O'Sullivan SE. A Novel Transwell Blood Brain Barrier Model Using Primary Human Cells. Front Cell Neurosci. 2019;13:230.

120. Lee SWL, Campisi M, Osaki T, Possenti L, Mattu C, Adriani G, et al. Modeling nanocarrier transport across a 3D in vitro human blood-brainbarrier microvasculature. Adv Healthc Mater. 2020;9:e1901486.

121. Puscas I, Bernard-Patrzynski F, Jutras M, Lecuyer MA, Bourbonniere L, Prat A, et al. IVIVC assessment of two mouse brain endothelial cell models for drug screening. Pharmaceutics. 2019;11(11):587. 
122. Hong L, Xu C, O'Neal S, Bi HC, Huang M, Zheng W, et al. Roles of P-glycoprotein and multidrug resistance protein in transporting para-aminosalicylic acid and its $\mathrm{N}$-acetylated metabolite in mice brain. Acta Pharmacol Sin. 2014;35(12):1577-85.

123. Nakagawa S, Deli MA, Kawaguchi H, Shimizudani T, Shimono T, Kittel A, et al. A new blood-brain barrier model using primary rat brain endothelial cells, pericytes and astrocytes. Neurochem Int. 2009;54(3-4):253-63.

124. Man S, Tucky B, Bagheri N, Li X, Kochar R, Ransohoff RM. alpha4 Integrin/FN-CS1 mediated leukocyte adhesion to brain microvascular endothelial cells under flow conditions. J Neuroimmunol. 2009;210(1-2):92-9.

125. Subramanian S, Ugoya SO, Zhao Z, McRobb LS, Grau GE, Combes $V$, et al. Stable thrombus formation on irradiated microvascular endothelial cells under pulsatile flow: pre-testing annexin V-thrombin conjugate for treatment of brain arteriovenous malformations. Thromb Res. 2018;167:104-12.

126. Cucullo L, Couraud PO, Weksler B, Romero IA, Hossain M, Rapp E, et al. Immortalized human brain endothelial cells and flow-based vascular modeling: a marriage of convenience for rational neurovascular studies. J Cereb Blood Flow Metab. 2008;28(2):312-28.

127. Cucullo L, Hossain M, Rapp E, Manders T, Marchi N, Janigro D. Development of a humanized in vitro blood-brain barrier model to screen for brain penetration of antiepileptic drugs. Epilepsia. 2007;48(3):505-16.

128. Santaguida S, Janigro D, Hossain M, Oby E, Rapp E, Cucullo L. Side by side comparison between dynamic versus static models of blood-brain barrier in vitro: a permeability study. Brain Res. 2006;1109(1):1-13.

129. Jeong S, Kim S, Buonocore J, Park J, Welsh CJ, Li J, et al. A three-dimensional arrayed microfluidic blood-brain barrier model with integrated electrical sensor array. IEEE Trans Biomed Eng. 2018;65(2):431-9.

130. Adriani G, Ma D, Pavesi A, Kamm RD, Goh EL. A 3D neurovascular microfluidic model consisting of neurons, astrocytes and cerebral endothelial cells as a blood-brain barrier. Lab Chip. 2017;17(3):448-59.

131. Wolff A, Antfolk M, Brodin B, Tenje M. In vitro blood-brain barrier models-an overview of established models and new microfluidic approaches. J Pharm Sci. 2015;104(9):2727-46.

132. De Jong E, Williams DS, Abdelmohsen L, Van Hest JCM, Zuhorn IS. A filter-free blood-brain barrier model to quantitatively study transendothelial delivery of nanoparticles by fluorescence spectroscopy. J Control Release. 2018;289:14-22.

133. Deosarkar SP, Prabhakarpandian B, Wang B, Sheffield JB, Krynska B, Kiani MF. A novel dynamic neonatal blood-brain barrier on a chip. PLoS ONE. 2015;10(11):e0142725

134. Booth $\mathrm{R}$, Kim H. Characterization of a microfluidic in vitro model of the blood-brain barrier (muBBB). Lab Chip. 2012;12(10):1784-92.

135. Cho H, Seo JH, Wong KH, Terasaki Y, Park J, Bong K, et al. Three-dimensional blood-brain barrier model for in vitro studies of neurovascular pathology. Sci Rep. 2015;5:15222.

136. Brown JA, Pensabene V, Markov DA, Allwardt V, Neely MD, Shi M, et al. Recreating blood-brain barrier physiology and structure on chip: a novel neurovascular microfluidic bioreactor. Biomicrofluidics. 2015;9(5):054124.

137. Prabhakarpandian B, Shen MC, Nichols JB, Mills IR, Sidoryk-Wegrzynowicz M, Aschner M, et al. SyM-BBB: a microfluidic blood-brain barrier model. Lab Chip. 2013;13(6):1093-101.

138. Oddo A, Peng B, Tong Z, Wei Y, Tong WY, Thissen $H$, et al. Advances in microfluidic blood-brain barrier (bbb) models. Trends Biotechnol. 2019;37(12):1295-314

139. Griep $L M$, Wolbers F, de Wagenaar B, ter Braak PM, Weksler BB, Romero IA, et al. BBB on chip: microfluidic platform to mechanically and biochemically modulate blood-brain barrier function. Biomed Microdevices. 2013:15(1):145-50.

140. Park TE, Mustafaoglu N, Herland A, Hasselkus R, Mannix R, FitzGerald EA, et al. Hypoxia-enhanced Blood-brain Barrier Chip recapitulates human barrier function and shuttling of drugs and antibodies. Nat Commun. 2019;10(1):2621

141. DeStefano JG, Xu ZS, Williams AJ, Yimam N, Searson PC. Effect of shear stress on iPSC-derived human brain microvascular endothelial cells (dhBMECs). Fluids Barriers CNS. 2017;14(1):20.
142. Grifno GN, Farrell AM, Linville RM, Arevalo D, Kim JH, Gu L, et al. Tissueengineered blood-brain barrier models via directed differentiation of human induced pluripotent stem cells. Sci Rep. 2019;9(1):13957.

143. Neal EH, Marinelli NA, Shi Y, McClatchey PM, Balotin KM, Gullett DR, et al. A simplified, fully defined differentiation scheme for producing bloodbrain barrier endothelial cells from human iPSCs. Stem Cell Reports. 2019;12(6):1380-8.

144. Kaisar MA, Sajja RK, Prasad S, Abhyankar W, Liles T, Cucullo L. New experimental models of the blood-brain barrier for CNS drug discovery. Expert Opin Drug Discov. 2017;12(1):89-103.

145. Jiang L, Li S, Zheng J, Li Y, Huang H. Recent progress in microfluidic models of the blood-brain barrier. Micromachines. 2019;10(6):375.

146. Vatine GD, Barrile R, Workman MJ, Sances S, Barriga BK, Rahnama M, et al. Human iPSC-derived blood-brain barrier chips enable disease modeling and personalized medicine applications. Cell Stem Cell. 2019;24(6):995-1005.

147. Ohshima M, Kamei S, Fushimi H, Mima S, Yamada T, Yamamoto T. Prediction of drug permeability using in vitro blood-brain barrier models with human induced pluripotent stem cell-derived brain microvascular endothelial cells. Bioresour Open Access. 2019;8(1):200-9.

148. Foroutan S, Brillault J, Forbush B, O'Donnell ME. Moderate-to-severe ischemic conditions increase activity and phosphorylation of the cerebral microvascular endothelial cell $\mathrm{Na}+-\mathrm{K}+-\mathrm{Cl}$ - cotransporter. Am J Physiol Cell Physiol. 2005;289(6):C1492-501.

149. Yuen N, Lam TI, Wallace BK, Klug NR, Anderson SE, O'Donnell ME. Ischemic factor-induced increases in cerebral microvascular endothelial cell $\mathrm{Na} / \mathrm{H}$ exchange activity and abundance: evidence for involvement of ERK1/2 MAP kinase. Am J Physiol Cell Physiol. 2014;306(10):C931-42.

150. Ito U, Hakamata Y, Kawakami E, Oyanagi K. Degeneration of astrocytic processes and their mitochondria in cerebral cortical regions peripheral to the cortical infarction: heterogeneity of their disintegration is closely associated with disseminated selective neuronal necrosis and maturation of injury. Stroke. 2009;40(6):2173-81.

151. Friedman B, Schachtrup C, Tsai PS, Shih AY, Akassoglou K, Kleinfeld D, et al. Acute vascular disruption and aquaporin 4 loss after stroke. Stroke. 2009:40(6):2182-90.

152. Kleinschnitz C, Kraft P, Dreykluft A, Hagedorn I, Gobel K, Schuhmann $M K$, et al. Regulatory $T$ cells are strong promoters of acute ischemic stroke in mice by inducing dysfunction of the cerebral microvasculature. Blood. 2013;121(4):679-91.

153. Zhou W, Liesz A, Bauer H, Sommer C, Lahrmann B, Valous N, et al. Postischemic brain infiltration of leukocyte subpopulations differs among murine permanent and transient focal cerebral ischemia models. Brain Pathol. 2013;23(1):34-44.

154. Mori T, Tan J, Arendash GW, Koyama N, Nojima Y, Town T. Overexpression of human $\mathrm{S100B}$ exacerbates brain damage and periinfarct gliosis after permanent focal ischemia. Stroke. 2008;39(7):2114-21.

155. Dirnagl U, ladecola C, Moskowitz MA. Pathobiology of ischaemic stroke: an integrated view. Trends Neurosci. 1999;22(9):391-7.

156. Basuroy S, Leffler CW, Parfenova H. CORM-A1 prevents blood-brain barrier dysfunction caused by ionotropic glutamate receptor-mediated endothelial oxidative stress and apoptosis. Am J Physiol Cell Physiol. 2013;304(11):C1105-15

157. Itoh Y, Takaoka R, Ohira M, Abe T, Tanahashi N, Suzuki N. Reactive oxygen species generated by mitochondrial injury in human brain microvessel endothelial cells. Clin Hemorheol Microcirc. 2006:34(1-2):163-8.

158. Liu H, Wei X, Kong L, Liu X, Cheng L, Yan S, et al. NOD2 is involved in the inflammatory response after cerebral ischemia-reperfusion injury and triggers NADPH oxidase 2-derived reactive oxygen species. Int J Biol Sci. 2015;11(5):525-35.

159. Deli MA, Abraham CS, Kataoka Y, Niwa M. Permeability studies on in vitro blood-brain barrier models: physiology, pathology, and pharmacology. Cell Mol Neurobiol. 2005;25(1):59-127.

160. Chen J, Sun L, Ding GB, Chen L, Jiang L, Wang J, et al. Oxygen-glucose deprivation/reoxygenation induces human brain microvascular endothelial cell hyperpermeability via VE-cadherin internalization: roles of RhoA/ROCK2. J Mol Neurosci. 2019;69(1):49-59.

161. Ahmad S, Kindelin A, Khan SA, Ahmed M, Hoda MN, Bhatia K, et al. C3a receptor inhibition protects brain endothelial cells against oxygenglucose deprivation/reperfusion. Exp Neurobiol. 2019;28(2):216-28. 
162. Kokubu Y, Yamaguchi T, Kawabata K. In vitro model of cerebral ischemia by using brain microvascular endothelial cells derived from human induced pluripotent stem cells. Biochem Biophys Res Commun. 2017:486(2):577-83

163. Chen T, Dai SH, Li X, Luo P, Zhu J, Wang YH, et al. Sirt1-Sirt3 axis regulates human blood-brain barrier permeability in response to ischemia. Redox Biol. 2018;14:229-36.

164. Vemula S, Roder KE, Yang T, Bhat GJ, Thekkumkara TJ, Abbruscato TJ. A functional role for sodium-dependent glucose transport across the blood-brain barrier during oxygen glucose deprivation. J Pharmacol Exp Ther. 2009;328(2):487-95.

165. Andjelkovic AV, Stamatovic SM, Keep RF. The protective effects of preconditioning on cerebral endothelial cells in vitro. J Cereb Blood Flow Metab. 2003:23(11):1348-55.

166. Alluri H, Anasooya Shaji C, Davis ML, Tharakan B. Oxygen-glucose deprivation and reoxygenation as an in vitro ischemia-reperfusion injury model for studying blood-brain barrier dysfunction. J Vis Exp. 2015;99:e52699.

167. Gesuete R, Orsini F, Zanier ER, Albani D, Deli MA, Bazzoni G, et al. Glial cells drive preconditioning-induced blood-brain barrier protection. Stroke. 2011;42(5):1445-53.

168. Plateel M, Dehouck MP, Torpier G, Cecchelli R, Teissier E. Hypoxia increases the susceptibility to oxidant stress and the permeability of the blood-brain barrier endothelial cell monolayer. J Neurochem. 1995;65(5):2138-45.

169. Rybachuk O, Kopach O, Krotov V, Voitenko N, Pivneva T. Optimized model of cerebral ischemia in situ for the long-lasting assessment of hippocampal cell death. Front Neurosci. 2017;11:388.

170. Tiede LM, Cook EA, Morsey B, Fox HS. Oxygen matters: tissue culture oxygen levels affect mitochondrial function and structure as well as responses to HIV viroproteins. Cell Death Dis. 2011;2:e246.

171. Li S, Sun X, Xu L, Sun R, Ma Z, Deng X, et al. Baicalin attenuates in vivo and in vitro hyperglycemia-exacerbated ischemia/reperfusion injury by regulating mitochondrial function in a manner dependent on AMPK. Eur J Pharmacol. 2017:815:118-26.

172. Sladojevic N, Stamatovic SM, Keep RF, Grailer JJ, Sarma JV, Ward PA, et al. Inhibition of junctional adhesion molecule-A/LFA interaction attenuates leukocyte trafficking and inflammation in brain ischemia/reperfusion injury. Neurobiol Dis. 2014;67:57-70.

173. Zhang W, Smith C, Howlett C, Stanimirovic D. Inflammatory activation of human brain endothelial cells by hypoxic astrocytes in vitro is mediated by IL-1 beta. J Cereb Blood Flow Metab. 2000;20(6):967-78.

174. Zille M, Ikhsan M, Jiang Y, Lampe J, Wenzel J, Schwaninger M. The impact of endothelial cell death in the brain and its role after stroke: a systematic review. Cell Stress. 2019;3(11):330-47.

175. Neuhaus W, Burek M, Djuzenova CS, Thal SC, Koepsell H, Roewer N, et al. Addition of NMDA-receptor antagonist MK801 during oxygen/glucose deprivation moderately attenuates the upregulation of glucose uptake after subsequent reoxygenation in brain endothelial cells. Neurosci Lett. 2012;506(1):44-9.

176. Shi Y, Jiang X, Zhang L, Pu H, Hu X, Zhang W, et al. Endothelium-targeted overexpression of heat shock protein 27 ameliorates blood-brain barrier disruption after ischemic brain injury. Proc Natl Acad Sci USA. 2017;114(7):E1243-52.

177. Sladojevic N, Stamatovic SM, Johnson AM, Choi J, Hu A, Dithmer S, et al. Claudin-1-dependent destabilization of the blood-brain barrier in chronic stroke. J Neurosci. 2019;39(4):743-57.

178. Kangwantas K, Pinteaux E, Penny J. The extracellular matrix protein laminin-10 promotes blood-brain barrier repair after hypoxia and inflammation in vitro. J Neuroinflammation. 2016;13:25.

179. Nakagawa S, Aruga J. Sphingosine 1-phosphate signaling is involved in impaired blood-brain barrier function in ischemia-reperfusion injury. Mol Neurobiol. 2020;57(3):1594-606.

180. Chou CH, Modo M. Characterization of gene expression changes in human neural stem cells and endothelial cells modeling a neurovascular microenvironment. Brain Res Bull. 2020;158:9-19.

181. Albekairi TH, Vaidya B, Patel R, Nozohouri S, Villalba H, Zhang Y, et al. Brain delivery of a potent opioid receptor agonist, biphalin during ischemic stroke: role of organic anion transporting polypeptide (OATP). Pharmaceutics. 2019;1 1(9):467.
182. Tornabene E, Helms HCC, Pedersen SF, Brodin B. Effects of oxygenglucose deprivation (OGD) on barrier properties and mRNA transcript levels of selected marker proteins in brain endothelial cells/astrocyte co-cultures. PLOS ONE. 2019;14(8):e0221103.

183. Keep RF, Zhou N, Xiang J, Andjelkovic AV, Hua Y, Xi G. Vascular disruption and blood-brain barrier dysfunction in intracerebral hemorrhage. Fluids Barriers CNS. 2014;11:18.

184. Qu J, Zhao H, Li Q, Pan P, Ma K, Liu X, et al. MST1 suppression reduces early brain injury by inhibiting the NF-kappaB/MMP-9 pathway after subarachnoid hemorrhage in mice. Behav Neurol. 2018;2018:6470957.

185. Liu FD, Zhao R, Feng XY, Shi YH, Wu YL, Shen XL, et al. Rivaroxaban does not influence hemorrhagic transformation in a diabetes ischemic stroke and endovascular thrombectomy model. Sci Rep. 2018;8(1):7408.

186. Machida T, Takata F, Matsumoto J, Miyamura T, Hirata R, Kimura I, et al. Contribution of thrombin-reactive brain pericytes to blood-brain barrier dysfunction in an in vivo mouse model of obesity-associated diabetes and an in vitro rat model. PLoS ONE. 2017;12(5):e0177447.

187. Imai T, I wata S, Hirayama T, Nagasawa H, Nakamura S, Shimazawa M, et al. Intracellular Fe(2+) accumulation in endothelial cells and pericytes induces blood-brain barrier dysfunction in secondary brain injury after brain hemorrhage. Sci Rep. 2019;9(1):6228.

188. Wang J, Li C, Chen T, Fang Y, Shi X, Pang T, et al. Nafamostat mesilate protects against acute cerebral ischemia via blood-brain barrier protection. Neuropharmacology. 2016;105:398-410.

189. Blecharz-Lang KG, Wagner J, Fries A, Nieminen-Kelha M, Rosner J, Schneider UC, et al. Interleukin 6-mediated endothelial barrier disturbances can be attenuated by blockade of the IL6 receptor expressed in brain microvascular endothelial cells. TransI Stroke Res. 2018;9(6):631-42.

190. Winkler EA, Birk H, Burkhardt JK, Chen X, Yue JK, Guo D, et al. Reductions in brain pericytes are associated with arteriovenous malformation vascular instability. J Neurosurg. 2018;129(6):1464-74.

191. Wei S, Li Y, Polster SP, Weber CR, Awad IA, Shen L. Cerebral cavernous malformation proteins in barrier maintenance and regulation. Int J Mol Sci. 2020;21(2):675.

192. Malinverno M, Maderna C, Abu Taha A, Corada M, Orsenigo F, Valentino $M$, et al. Endothelial cell clonal expansion in the development of cerebral cavernous malformations. Nat Commun. 2019;10(1):2761.

193. Goodall EF, Wang C, Simpson JE, Baker DJ, Drew DR, Heath PR, et al. Age-associated changes in the blood-brain barrier: comparative studies in human and mouse. Neuropathol Appl Neurobiol. 2018;44(3):328-40.

194. Stamatovic SM, Martinez-Revollar G, Hu A, Choi J, Keep RF, Andjelkovic AV. Decline in Sirtuin-1 expression and activity plays a critical role in blood-brain barrier permeability in aging. Neurobiol Dis. 2019;126:105-16.

195. Yamazaki Y, Baker DJ, Tachibana M, Liu CC, van Deursen JM, Brott TG, et al. Vascular cell senescence contributes to blood-brain barrier breakdown. Stroke. 2016;47(4):1068-77.

196. Leclaire MD, Nettels-Hackert G, Konig J, Hohn A, Grune T, Uhlig CE, et al. Lipofuscin-dependent stimulation of microglial cells. Graefes Arch Clin Exp Ophthalmol. 2019;257(5):931-52.

197. Fan DNY, Schmitt CA. Genotoxic stress-induced senescence. Methods Mol Biol. 1896;2019:93-105

198. Lafontaine J, Tchakarska G, Rodier F, Mes-Masson AM. Necdin modulates proliferative cell survival of human cells in response to radiationinduced genotoxic stress. BMC Cancer. 2012;12:234.

199. Wang P, Zhang Z, Sun Y, Liu X, Tong T. The two isomers of HDTIC compounds from Astragali Radix slow down telomere shortening rate via attenuating oxidative stress and increasing DNA repair ability in human fetal lung diploid fibroblast cells. DNA Cell Biol. 2010;29(1):33-9.

200. James EL, Michalek RD, Pitiyage GN, de Castro AM, Vignola KS, Jones J, et al. Senescent human fibroblasts show increased glycolysis and redox homeostasis with extracellular metabolomes that overlap with those of irreparable DNA damage, aging, and disease. J Proteome Res. 2015;14(4):1854-71.

201. Rogers SC, Zhang X, Azhar G, Luo S, Wei JY. Exposure to high or low glucose levels accelerates the appearance of markers of endothelial cell senescence and induces dysregulation of nitric oxide synthase. J Gerontol A Biol Sci Med Sci. 2013;68(12):1469-81.

202. Thum T, Hoeber S, Froese S, Klink I, Stichtenoth DO, Galuppo P, et al. Age-dependent impairment of endothelial progenitor cells is corrected 
by growth-hormone-mediated increase of insulin-like growth-factor-1. Circ Res. 2007;100(3):434-43.

203. Geng J, Wang L, Zhang L, Qin C, Song Y, Ma Y, et al. Blood-brain barrier disruption induced cognitive impairment is associated with increase of inflammatory cytokine. Front Aging Neurosci. 2018;10:129.

204. Donato AJ, Black AD, Jablonski KL, Gano LB, Seals DR. Aging is associated with greater nuclear NF kappa B, reduced I kappa B alpha, and increased expression of proinflammatory cytokines in vascular endothelial cells of healthy humans. Aging Cell. 2008;7(6):805-12.

205. Arancio W. Progerin expression induces a significant downregulation of transcription from human repetitive sequences in iPSC-derived dopaminergic neurons. Geroscience. 2019;41(1):39-49.

206. Ling C, Liu Z, Song M, Zhang W, Wang S, Liu X, et al. Modeling CADASIL vascular pathologies with patient-derived induced pluripotent stem cells. Protein Cell. 2019;10(4):249-71.

207. Meguro T, Chen B, Lancon J, Zhang JH. Oxyhemoglobin induces caspase-mediated cell death in cerebral endothelial cells. J Neurochem. 2001;77(4):1128-35.

208. Zhang J, Dong B, Hao J, Yi S, Cai W, Luo Z. LncRNA Snhg3 contributes to dysfunction of cerebral microvascular cells in intracerebral hemorrhage rats by activating the TWEAK/Fn14/STAT3 pathway. Life Sci. 2019;237:116929.

209. Alabanza LM, Bynoe MS. Thrombin induces an inflammatory phenotype in a human brain endothelial cell line. J Neuroimmunol. 2012;245(1-2):48-55.

210. Festoff BW, Sajja RK, van Dreden P, Cucullo L. HMGB1 and thrombin mediate the blood-brain barrier dysfunction acting as biomarkers of neuroinflammation and progression to neurodegeneration in Alzheimer's disease. J Neuroinflammation. 2016;13(1):194.

211. Machida T, Dohgu S, Takata F, Matsumoto J, Kimura I, Koga M, et al. Role of thrombin-PAR1-PKCtheta/delta axis in brain pericytes in thrombininduced MMP-9 production and blood-brain barrier dysfunction in vitro. Neuroscience. 2017;350:146-57.

\section{Publisher's Note}

Springer Nature remains neutral with regard to jurisdictional claims in published maps and institutional affiliations.
Ready to submit your research? Choose BMC and benefit from:

- fast, convenient online submission

- thorough peer review by experienced researchers in your field

- rapid publication on acceptance

- support for research data, including large and complex data types

- gold Open Access which fosters wider collaboration and increased citations

- maximum visibility for your research: over $100 \mathrm{M}$ website views per year

At BMC, research is always in progress.

Learn more biomedcentral.com/submissions 